\title{
Industrial Applications of Pulsed Power Technology
}

\author{
Hidenori Akiyama, Takashi Sakugawa, Takao Namihira \\ Graduate School of Science and Technology, Kumamoto University, 2-39-1 Kurokami, Kumamoto 860-8555, Japan \\ Koichi Takaki \\ Department of Electrical and Electronic Engineering, Iwate University, Iwate 020-8551, Japan \\ Yasushi Minamitani \\ Department of Electrical Engineering, Yamagata University, Yamagata 992-8510, Japan \\ and Naoyuki Shimomura \\ Institute of Technology and Science, The University of Tokushima, Tokushima 770-8506, Japan
}

\begin{abstract}
A review of mainly the past two years is undertaken of the industrial applications of pulsed power. Repetitively operated pulsed power generators with a moderate peak power have been developed for industrial applications. These generators are reliable and have low maintenance. Development of the pulsed power generators helps promote industrial applications of pulsed power for such things as food processing, medical treatment, water treatment, exhaust gas treatment, ozone generation, engine ignition, ion implantation and others. Here, industrial applications of pulsed power are classified by application for biological effects, for pulsed streamer discharges in gases, for pulsed discharges in liquid or liquidmixture, and for material processing.
\end{abstract}

Index Terms - Pulsed power, industrial application, bioelectrics, exhaust gas treatment, discharge in liquid, material processing.

\section{INTRODUCTION}

PULSED power technology has mainly been developed for nuclear fusion studies and for military defense applications. For these studies, pulsed power generators have been developed with extremely high peak power and typically single shot operation. Recently, repetitively operated pulsed power generators with a moderate peak power have been developed. These generators are compact, reliable, low maintenance, and have high reproducibility. Many studies of industrial applications of pulsed power, such as food processing, medical treatment, water treatment, exhaust gas treatment, ozone generation, engine ignition, ion implantation and others, came about with the development of such a pulsed power generator.

In this paper, a review of mainly the past two years is undertaken of pulsed power generators and industrial applications of pulsed power. Discharge switches have been typically used in pulsed power generators with extremely high peak power. Power semiconductors and magnetic switches are commonly used in pulsed power generators for industrial applications. Various pulse power generators have been developed for each industrial application for which they are suitable [1-12]. Here, industrial applications of pulsed power are classified by application for biological effects [13-22], for pulsed streamer discharges in gases [23-58], for pulsed discharges in liquid or liquid-mixture [59-79], and for material processing [80-119].

Manuscript received on 13 April 2007, in final form 19 July 2007.

\section{PULSED POWER GENERATORS}

Many conventional pulsed power generators have been using discharge switches with a capacitor discharge circuit. These generators are based on single shot or low repetition rate operation and generate extremely high peak power. On the other hand, repetitively operated pulsed power generators with a moderate peak power have been developed for industrial applications. Also, a compact pulsed power system is required [1].

Recently, power semiconductor device technologies have improved the performance of fast and high-power switching devices. Semiconductor switches are used with the assistance of magnetic switches (for example, S1 and Ls in Figure 1) because the switches are not capable of driving typical generators directly. Repetitively operated generators consist of semiconductor switches, step-up pulse transformers, and magnetic switches. Here, recent progress of all solid-state pulsed power generators is reviewed with particular emphasis on industrial applications of pulsed power generator using semiconductor and magnetic switches.

Research and development on practical industrial applications of repetitive pulsed power generators have focused on microlithography light sources for a long time. In particular, an excimer laser and a high energy density plasma (extreme ultraviolet source) [2], which are used in semiconductor fabrication, require a high repetition rate, high 
stability, and a long lifetime. Therefore, most of the light sources for microlithography have been using an all solid-state pulsed power generator with a semiconductor switch and a magnetic switch for their driver [3]. It is necessary to evaluate the losses of the capacitor and magnetic switch core material [4-5]. The capacitor charging or discharging losses are related to the dissipation factor, the energy transfer per pulse, and the pulse repetition rate. Since new magnetic materials like nanocrystalline alloy is recently available, the optimal selection of magnetic switches for each compression stage is important.

Applications for environmental fields involving the decomposition of harmful gases, generation of ozone, and water treatment by discharge plasmas in water utilizing pulsed power discharges have been studied [3,6-9]. In these applications, repetitive operation and long lifetime are also necessary for pulsed power generators. The circuit of a magnetic pulse compressor (MPC) for treatment of pollutants in heterogeneous media is shown in Figure 1 [10]. The specifications of the primary switch S1 is shown in Table 1. The basic parameters are shown in Table 2. One magnetic pulse compression stage suffices to produce $60 \mathrm{kV}, 3 \mathrm{~J}$ pulses with a $15 \mathrm{~ns}$ risetime, $100 \mathrm{~ns}$ duration, and $500 \mathrm{~Hz}$ repetition frequency across a reactor that has a discharge impedance of approximately $100 \Omega$.

Table 1. The specifications of the primary switch S1 [10].

\begin{tabular}{|l|l|}
\hline \multicolumn{1}{|c|}{ Item } & \multicolumn{1}{c|}{ Value } \\
\hline Maximum charge voltage & $9 \mathrm{kVDC}$ \\
\hline Blocking voltage & $13.5 \mathrm{kV}$ \\
\hline Peak current & $2.5 \mathrm{kA}$ \\
\hline Maximum turn-off current & $<10 \mathrm{~A}$ \\
\hline Pulse duration & $1.5 \mu \mathrm{s}$ \\
\hline di/dt & $6 \mathrm{kA} / \mu \mathrm{s}$ \\
\hline Pulse repetition frequency & up to $1.3 \mathrm{kHz}$ \\
\hline
\end{tabular}

Table 2. The basic parameters of the high voltage output [10].

\begin{tabular}{|l|l|}
\hline \multicolumn{1}{|c|}{ Item } & \multicolumn{1}{c|}{ Value } \\
\hline Average power & $3-5 \mathrm{~kW}$ \\
\hline $\begin{array}{l}\text { Maximum voltage at } 100 \Omega \\
\text { (equivalent load) }\end{array}$ & $60 \mathrm{kV}$ \\
\hline Risetime & $15-20 \mathrm{~ns}$ \\
\hline Pulse width & $100 \mathrm{~ns}$ \\
\hline Pulse repetition frequency & $\begin{array}{l}\text { up to } 1 \mathrm{kHz} \\
(3-5 \mathrm{~J} / \mathrm{shot})\end{array}$ \\
\hline
\end{tabular}

Pulsed electric field (PEF) generation is a promising technology for non-thermal disinfection of water. A typical pulsed power modulator circuit is shown in Figure 2 [11]. The step-up pulse transformer increases the peak voltage to a maximum of $20 \mathrm{kV}$ at a repetition rate of $2 \mathrm{kHz}$.

Another application involves biological cell response for nanosecond pulsed electric field exposures [12]. The charging of the cell membranes in response to ultra short pulsed high electric fields was studied. The experimental setup is shown in Figure 3. A fast semiconductor switch (MOSFET) was chosen as a switch in a Blumlein line pulse generator. The voltage applied to the electrodes is $1 \mathrm{kV}$, corresponding to a maximum electric field of $100 \mathrm{kV} / \mathrm{cm}$ in the $100 \mu \mathrm{m}$ gap. The pulse duration is $60 \mathrm{~ns}$ with a rise- and fall- time of about 2-5 ns.

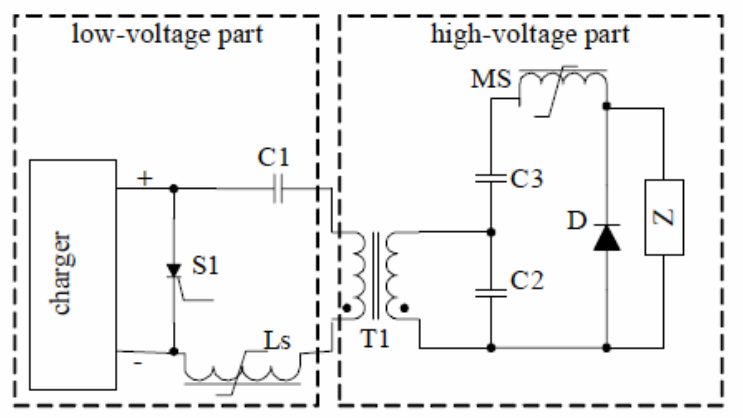

Figure 1. The circuit of a magnetic pulse compressor (MPC) for treatment of pollutants [10].

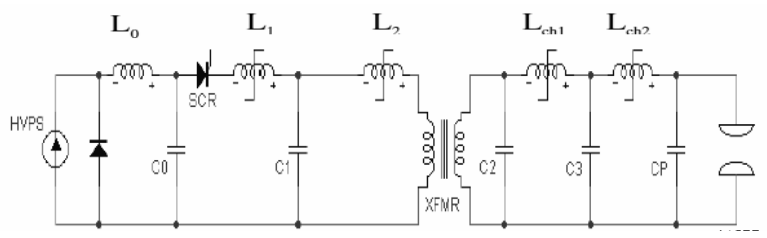

Figure 2. A typical pulsed power modulator circuit for water sterilization [11].

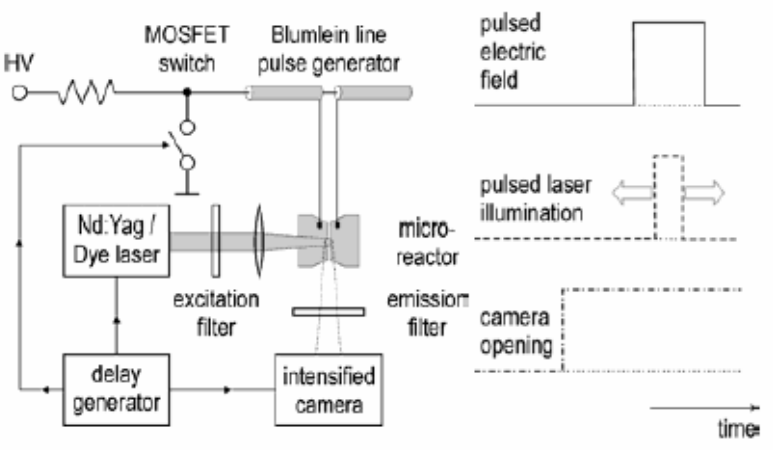

Figure 3. Experimental setup and diagnostic principle [12].

\section{BIOLOGICAL APPLICATIONS}

Industrial fields using biological effects of pulsed power technologies can be categorized as decontamination of air and water, crop growth, food processing, and medical treatment. Types of pulsed power that have biological effects are gas discharges, water discharges, and electromagnetic fields. The discharges yield free radicals, UV radiation, and shock waves. The electromagnetic field yields electroporation of the cell membrane or influences the cell nuclei. Biological applications of pulsed power are performed by selecting the type that gives the target objects the adequate result from among these agents or byproducts. 
Gas discharges are selected for sterilization of Escherichia coli and other bacteria for decontamination of air. A pulsed streamer discharge that is generated at a wire or pin electrodes has been used for such purposes. A diffuse pulsed discharge at atmosphere that is used for excitation of pulsed lasers was studied for sterilization by Shcolnikov et al [13]. The pulsed voltage is able to make a diffuse discharge without a spark discharge. The diffuse discharge is useful for covering a large discharge area for making free radicals. Shcolnikov used three electrodes to obtain the diffuse discharge at atmospheric pressure.

Water discharges and pulsed electromagnetic fields are selected for sterilization or inactivation of bacteria in water decontamination. A streamer discharge is usually used in water. The streamer discharge can generate free radicals, UV radiation, strong electric field and shock waves. These agents have been shown to effectively sterilize bacteria. Additionally, Baroch et al used spark discharges to degrade Escherichia coli and staphylococcus aureus [14].

$\mathrm{Z}$. Li et al studied inactivation of cyanobacteria in water by using streamer discharges [15]. A voltage of $160 \mathrm{kV}$ with a pulse width of $2 \mu \mathrm{s}$ was used to generate the streamer discharge. Only a single discharge made $\mathrm{M}$. aeruginosa sink to the bottom of chamber. They concluded that the dominant agents for inactivation of cyanobacteria are shockwave and the discharge current.

For decontamination of water, a three phase method of gas, liquid, and solid was proposed by R. Zhang et al [16]. The reactor was a packed-bed type with a barrier electrode. The water inlet and outlet were set at the upper and lower sides, respectively. Conversely, the gas inlet and outlet were set at lower and upper sides, respectively. The three-phase discharge was then performed to sterilize Escherichia coli.

For biological applications of pulsed electromagnetic field, electroporation is usually used to sterilize bacteria. This technique is commonly applied for sterilization in food processing. El-Hag et al investigated inactivation of microorganisms naturally contaminated in orange juice [17]. The naturally contaminated microorganisms in orange juice are more difficult to inactivate by PEF than added unnatural microorganisms. They showed that the reduction ratio of natural microorganisms increased by a synergistic effect between the PEF strength and temperature as shown in Table 3. The industrial-scale electroporation of sugar beat has been done in order to replace the thermal denaturation process [18].

For crop growth, gas discharges were used for cultivation of mushrooms by Tsukamoto et al [19]. They used a spark discharge applied to sawdust pots used for planting fungus. The group with the applied spark discharge had a twofold gain of Shiitake (Lentinula edodes) mushrooms. Other mushrooms were also investigated by applying a spark discharge. Those were buna-shimeji (Hypsizygus marmoreus) mushroom and eringi (Pleurotus eryngii) mushroom. The crops of those mushrooms increased $15 \%$ by applying the spark discharge as shown in Figure 4.
Table 3. Effect of temperature rise on the reduction of microorganisms in contaminated orange juice [17].

\begin{tabular}{|l|c|c|c|}
\hline Temperature, ${ }^{\circ} \mathrm{C}$ & untreated & 23 & 45 \\
\hline Electric field level, kV/cm & untreated & 46.7 & 40.0 \\
\hline $\begin{array}{l}\text { Count on plate count agar, } \\
\text { log cfu/mL }\end{array}$ & 7.91 & 6.37 & 6.20 \\
\hline $\begin{array}{l}\text { Count on potato dextrose agar, } \\
\text { log cfu/mL }\end{array}$ & 7.01 & 5.70 & 4.84 \\
\hline
\end{tabular}

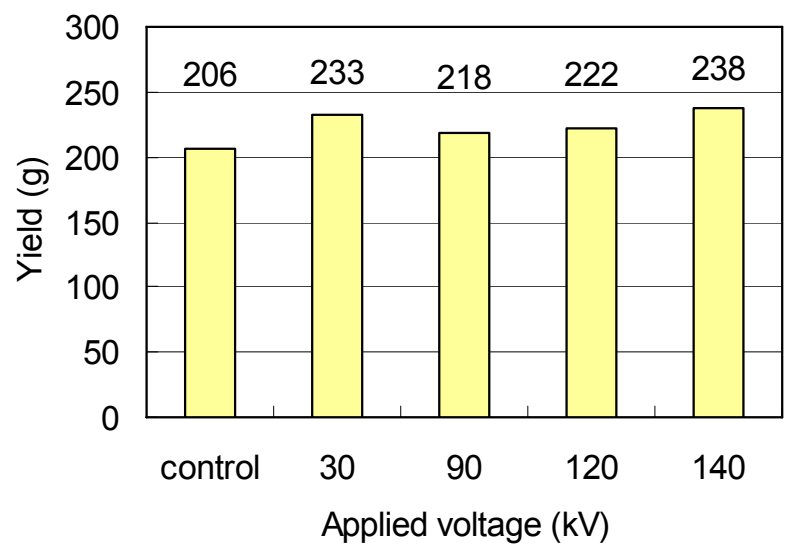

(a) buna-shimeji (Hypsizygus marmoreus)



(b) eryngii (Pleurotus eryngii)

Figure 4. Effect of electrical stimulus on mushroom growth. "Control" means the case without a spark discharge [19].

For medical treatments, electromagnetic field has attracted attention for cancer treatment. Electroporation by pulsed power has been known for the medical application of gene manipulation since early times. Recently, many researchers have interests in using shorter pulse durations. The electrode microchamber with dimensions suitable for live mammalian cell has been studied [20]. Extremely short pulse electric fields or high frequency electric fields that are greater than 10 $\mathrm{MHz}$ can be applied to the nucleoplasm. Then apotosis of the cancer cell can be induced. Recently, many studies are being performed on the effect of a pulse electric field on a cancer cell. Nuccitelli et al applied a pulse electric field to melanomas in a mouse and showed that a nanosecond pulse electric field caused cell death of the melanomas in the mouse 
[21]. The effects to the cell were also investigated by others. Nomura et al. investigated the effect of intense burst ac electric field on the cell [22]. They showed that a burst electric field of about $25 \mathrm{kHz}$ on the cell caused electroporation. On the contrary, a burst electric field of about $50 \mathrm{MHz}$ caused fragmentation or degradation of DNA within the cell.

\section{TREATMENT OF EXHAUST GASES BY PULSED STREAMER DISCHARGE}

Recently, nonthermal plasmas, in which the mean energy of the electrons is higher than that of the ions and the neutrals in gas, have been increasingly used to control harmful gases [23$26]$ and to generate ozone $\left(\mathrm{O}_{3}\right)[27,28]$. Nonthermal plasmas have many kinds of chemically activate radicals, such as $\mathrm{O}$, $\mathrm{O}_{3}, \mathrm{~N}, \mathrm{~N}^{*}, \mathrm{~N}_{2}^{+}$and $\mathrm{OH}$, which are generated by the dissociation and ionization of the ambient gases caused by the impact of energetic electrons. Using pulsed power technology, nonthermal plasmas have been generated by a pulsed electron beam [29] or a pulsed streamer discharge [30], and have been used to treat nitric oxides $\left(\mathrm{NO}_{\mathrm{X}}\right)$ [31-34], sulfur dioxide $\left(\mathrm{SO}_{2}\right)$ [35-37], carbon dioxide $\left(\mathrm{CO}_{2}\right)$ [38] and volatile organic compounds (VOCs) [39, 40], and to generate ozone [41-46]. Particularly, the treatment of exhaust gases $\left(\mathrm{NO}_{\mathrm{X}}\right.$ and $\left.\mathrm{SO}_{2}\right)$ using a pulsed streamer discharge has been studied for the past decade. This section explains the present status.

After the industrial revolution, the consumption of fossil fuel energy increased rapidly and caused environmental pollution. As a result, it became very important to protect the environment and to develop technologies with less energy consumption and less pollutant exhaust. Figure 5 shows the typical experimental set-up for exhaust gas treatment by a pulsed streamer discharge [47]. Gas cylinders of nitrogen $\left(\mathrm{N}_{2}\right)$, oxygen $\left(\mathrm{O}_{2}\right), \mathrm{N}_{2}$ mixed with $\mathrm{NO}$, and $\mathrm{N}_{2}$ mixed with $\mathrm{SO}_{2}$ and $\mathrm{H}_{2} \mathrm{O}$ are used to simulate the exhaust gases from a thermal power station, a diesel engine, and other sources. The typical electrode geometries of the discharge reactors are coaxial, line to plane, and point to plane. Generally, a magnetic pulse compressor, a multi-staged Blumlein line, and a simple capacitor discharge system are utilized as the pulsed power supply. Before and after the discharge treatment, the concentrations of $\mathrm{NO}, \mathrm{NO}_{2}$ and $\mathrm{SO}_{2}$ are measured using gas analysis instruments to investigate the removal ratio and removal energy efficiency of the pollutants. During the

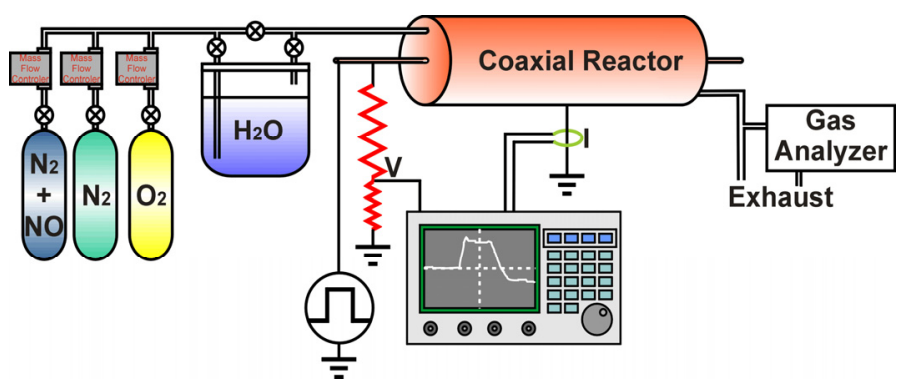

Figure 5. Experimental set-up for simulated gas treatment [47].

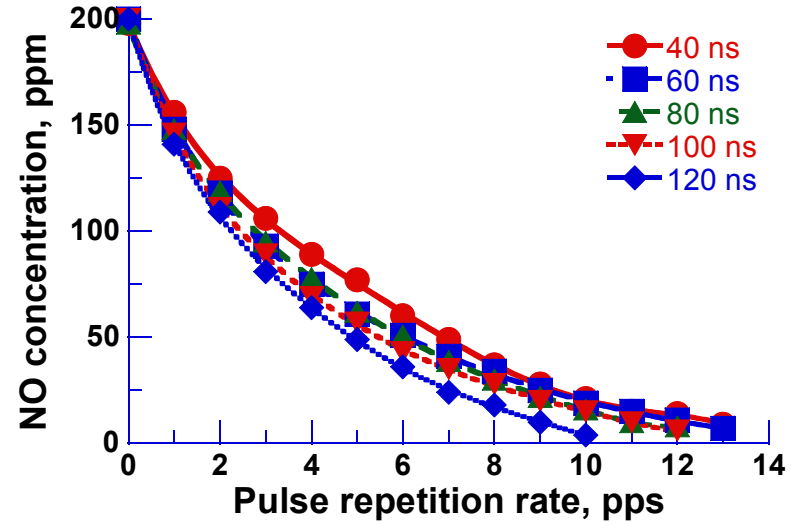

Figure 6. Concentrations of $\mathrm{NO}$ as a function of pulse repetition rate and for different pulse widths [47]. Pulse width: • $40 \mathrm{ns,} 60 \mathrm{~ns}, 80 \mathrm{~ns}, \boldsymbol{\Delta} 100 \mathrm{~ns}$, $\nabla 120$ ns.

experiment, the applied voltage and discharge current into the reactor are monitored by oscilloscope via voltage and current probes to calculate the consumption energy.

Figure 6 shows the dependence of NO concentration on the pulse repetition rate for different pulse durations in an experiment with a three-staged Blumlein line pulsed power generator having a $300 \Omega$ characteristic impedance, a simulated gas composition of $200 \mathrm{ppmNO} / 5 \% \mathrm{O}_{2} / 4 \% \mathrm{H}_{2} \mathrm{O}$ and balance of $\mathrm{N}_{2}$, gas temperature of $298 \mathrm{~K}$, and a gas flow rate of $2.0 \mathrm{~L} / \mathrm{min}$ at $273 \mathrm{~K}$ and $1.01 \times 10^{5} \mathrm{MPa}$ [47]. Observe in Figure 6 that the concentration of NO decreases with increasing pulse repetition rate. This is because the radicals which react with $\mathrm{NO}$ increase with the repetition rate. It is also understood that the reduced molecules of NO gradually saturate with increasing pulse repetition rate. This saturation is caused by a decrease of the reaction rate between the radicals and NO at the higher NO removal ratio. These phenomena are generally observed in pollutant removal experiments. The key factors to decrease energy consumption to decompose pollutants are explained in the following sections.

\subsection{PULSED DURATION}

The energy efficiency for NO removal improves with shorter pulse duration [47]. From the streak image of a pulsed streamer discharge in a coaxial electrode geometry [48, 49], the propagation process of the pulsed streamer discharge is that the primary streamer initiates in the vicinity of the central rod electrode and then propagates toward the grounded cylinder electrode. When the primary streamers lose contact with the central rod electrode, secondary streamers initiate in the vicinity of the central rod electrode since the electric field at the central rod surface becomes high enough to generate streamers with the disappearance of the interaction between the electric fields of the central rod electrode and the primary streamers. The secondary streamers propagate toward the ground electrode with higher velocity than that of the primary streamers. This is because the secondary streamers move in the plasma channels already produced by the primary streamers. The secondary streamers, however, stop 
propagating in the middle of the electrode gap because the electric field is insufficient to sustain ionization once the primary streamers reach the outer cylinder electrode. After full development of the primary streamers in the electrode gap, the discharge phase changes to a glow-like discharge in the plasma channel produced by the primary streamers.

The reason for the higher energy efficiency of NO removal with a shorter pulse duration is that the reactive radicals are generated more efficiently during the initial phase (during the primary streamer propagation) of the pulsed streamer discharge. Currently, nanosecond pulsed power generators having a maximum voltage of $100 \mathrm{kV}$ and a duration of several ns have been developed to create pulsed streamer discharges consisted of only the primary streamer to reduce the energy consumption for NO removal [50-52].

\subsection{CHEMICAL ADDITIVE}

Chemical additives, such as ammonia, propene, and others, are often used to cause a chain reaction for pollutant decomposition in a nonthermal plasma. In studies, the chemical additives are injected at the inlet of a discharge reactor. Figure 7 shows the dependence of NO removal ratio on the input energy density [53]. It is found from Fig. 7 that the addition of propene improves the NO removal ratio for the same input energy density. The NO removal ratio increased from $60 \%$ to $80 \%$ at $3 \mathrm{Wh} / \mathrm{Nm}^{3}$. It is also reported that the addition of methyl alcohol, ethyl alcohol, 1-propanol, Butyl alcohol, pentyl alcohol, pentane, hexane, heptane, octane, ethylene or propylene has a similar positive influence on the energy efficiency of NO removal $[54,55]$. Ammonia as an additive also reduces the consumption energy to remove NO [56]. For ammonia addition, it is noted that the aerosols of the ammonia salts of ammonium nitrate and cupric ammonium nitrate were generated as byproducts.

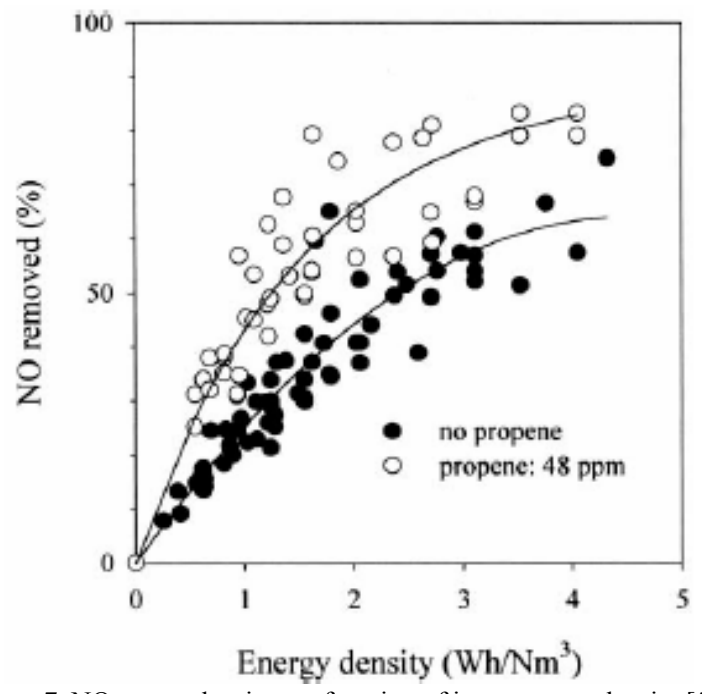

Figure 7. NO removal ratio as a function of input energy density [53].

\subsection{CATALYST}

For NO removal by nonthermal plasma, most of the NO are oxidized into nitric dioxide $\left(\mathrm{NO}_{2}\right)$ and therefore the removal ratio of total nitric oxides $\left(\mathrm{NO}_{\mathrm{X}}=\mathrm{NO}+\mathrm{NO}_{2}\right)$ is quite low. However, it is well known that $\mathrm{NO}_{2}$ reacts with hydrocarbons on a catalyst surface and is de-oxidized to $\mathrm{N}_{2}$. Figure 8 shows the gas composition (FT-IR spectra), which shows the effect of a catalyst only, plasma only, and plasma plus catalyst combination on $\mathrm{NO}_{\mathrm{X}}$ and hydrocarbons [57]. In this case, propene is used as the hydrocarbon reactant. From the figure of the catalyst only, there is no change in gas composition by only passing the catalyst. For plasma only, all NO is oxidized into $\mathrm{NO}_{2}$ and part of the propene is oxidized into formaldehyde. For the combination of plasma and catalyst, $\mathrm{NO}_{2}$ oxidized by the discharge passes the catalyst with the hydrocarbon, and $\mathrm{NO}_{\mathrm{X}}$ and the hydrocarbon are perfectly treated. In addition, it has recently been reported that a nonthermal plasma can enhance the performance of selective catalytic reduction at relatively lower temperatures than the normal working temperature [58].

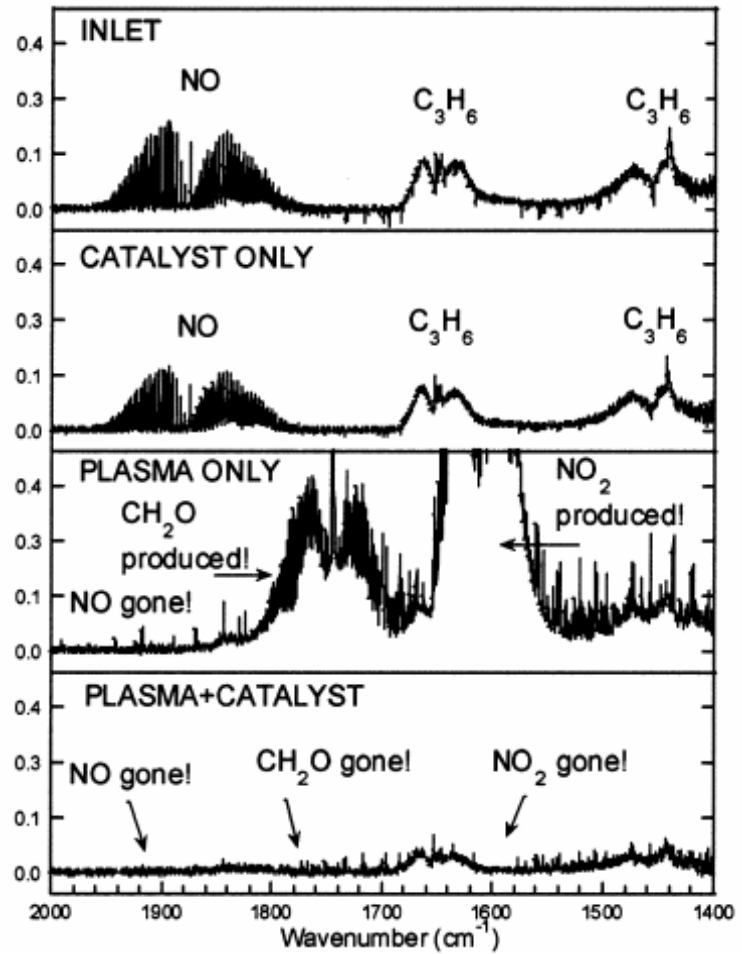

Figure 8. Fourier Transform Infrared (FTIR) spectroscopy data showing the effect of catalyst, plasma, and plasma plus catalyst combination on $\mathrm{NO}_{\mathrm{X}}$ and hydrocarbons [57].

\section{PULSED DISCHARGES IN LIQUID- MIXTURE}

Industrial applications using pulsed discharges in liquid or liquid-mixture are described here, excluding biological- and medical-related applications. Additionally, applications for pulsed power systems such as switches and insulation are described.

The most typical application of pulsed discharges in liquid or liquid-mixture is water treatment. The objects of treatment are in various fields, such as for waterworks, sewage, river, lake and industrial drainage. The characteristics of a pulsed 
discharge plasma in water have been investigated by $\mathrm{T}$. Namihira, et al.[59]. They designed a maintenance-free pulse generator using magnetic pulse compression to produce discharges in water as shown in Figure 9. The temperature and electron density of the plasma were calculated to be $15,000 \mathrm{~K}$ and $10^{18} / \mathrm{cm}^{3}$, respectively. Kadowaki, et al studied the initiation and propagation of streamer discharges by reciprocal voltage pulse trains [60]. It was found that $\mathrm{OH}$ radicals were produced in the experiment. Choi et al have been developing a pulsed power generator by using EMTP simulation to produce discharges in water [61]. The generator consists of a magnetic pulse compressor (MPC) and a Blumlein-type pulse forming network (BPFN).

Using discharges in gas with droplets of water or in an aerosol as well as in water have been suggested for water treatment. Minamitani et al [62] effectively decomposed the dye indigo carmine by pulsed corona discharges in gas with a water droplets spray. The pulsed corona was produced in a coaxial reactor consisting of wire-cylinder electrodes, and the droplets with indigo carmine were sprayed axially. High removal rates of phenol were achieved by Pokryvailo et al, using an aerosol reactor and a corona above the water (CAW) [59]. Their best results were $33 \%$ conversion with a yield of $200 \mathrm{~g} / \mathrm{kWh}$ using four CAW modules and $99 \%$ conversion with a yield of $18 \mathrm{~g} / \mathrm{kWh}$ using an aerosol reactor (Figure 10). They considered the system for water treatment and demonstrated reliable all-solid-state compact nanosecond pulsers.

There are also applications of water treatment using pulsed electric fields. Treatment systems for continuous flowing water by pulsed electric field (PEF) have been designed by two groups; Gaudreau et al [64], and Narsetti et al [11].

Acoustic phenomena such as a shockwave also occur with discharges in liquid. Mackersie et al studied high-power ultrasound (HPU) generation by spark discharges in water [65]. The formation and collapse of bubbles generated by the electric spark in water were discussed, and the effects from HPU output were investigated. They concluded that maximizing the source dimension is more advantageous than increasing the applied pulse energy. Sunka et al developed an apparatus to generate two successive shock waves focusing on a common focal point for medical application [66].

Ignition in engines is not only one of the traditional applications of spark discharges but an application for discharges in a gas-liquid mixture. Wang et al applied pulsed power technique to the ignition in engine [67]. Nanosecond transient plasmas have been applied to the ignition of hydrocarbon-air mixtures under quiescent and dynamic fill conditions and within combustion chamber geometries.

Pulsed electrical breakdown phenomena in liquid have also been applied to many fields including high-voltage switching, high-voltage insulation, and energy storage, though they are not direct industrial applications. Typical characteristics of liquids are high electric field strength and/or a large dielectric constant. Wetz et al investigated the effects of surface conditioning, field enhancements, and charge injection on pulsed breakdown strength of water [68, 69]. Dielectric strength of sub-millimeter water gaps using microsecond and sub-microsecond voltage pulses was experimentally studied by $\mathrm{Lu}$ et al [70] and was simulated by Qian et al [71].

Development of the switches using water as medium is in full development. The switches allow for compact generators and it is possible to achieve a fast pulse rise time. Cassany and Voisin discussed reproducibility improvement of high voltage self-break water switches [72]. A $170 \mathrm{kV}$ laser-triggered water switch was developed by Woodworth, et al [73]. They obtained Schlieren photographs of the laser-induced breakdown and considered the effect of a string of hot dense point plasmas formed with the laser, as shown in Figure 11. Qian et al studied self- and laser-triggered electrical breakdown of liquid water with numerical calculations [74].

Xiao et al has investigated the electrical breakdown and dielectric recovery of propylene carbonate as well as water $[75,76]$. Other liquids can also be used as the medium of a switch or insulators and bring various features. Oil switches have been developed by Curry et al [77, 78]. Poly-a olefin synthetic oil was tested as a switching medium by Norgard et al [79].



Figure 9. Typical still photograph of a discharge induced in water [59].

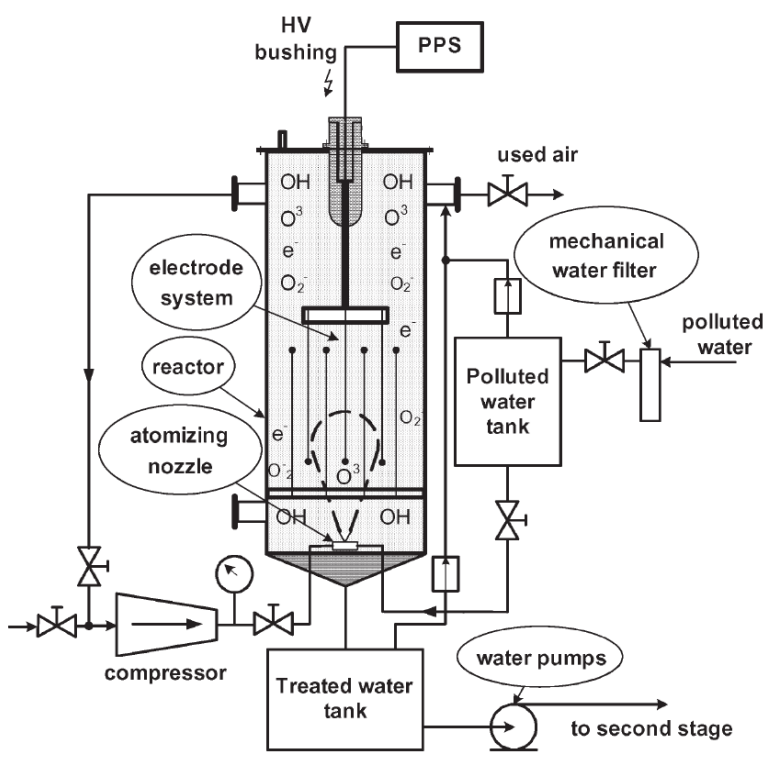

Figure 10. System for polluted water treatment [63]. 


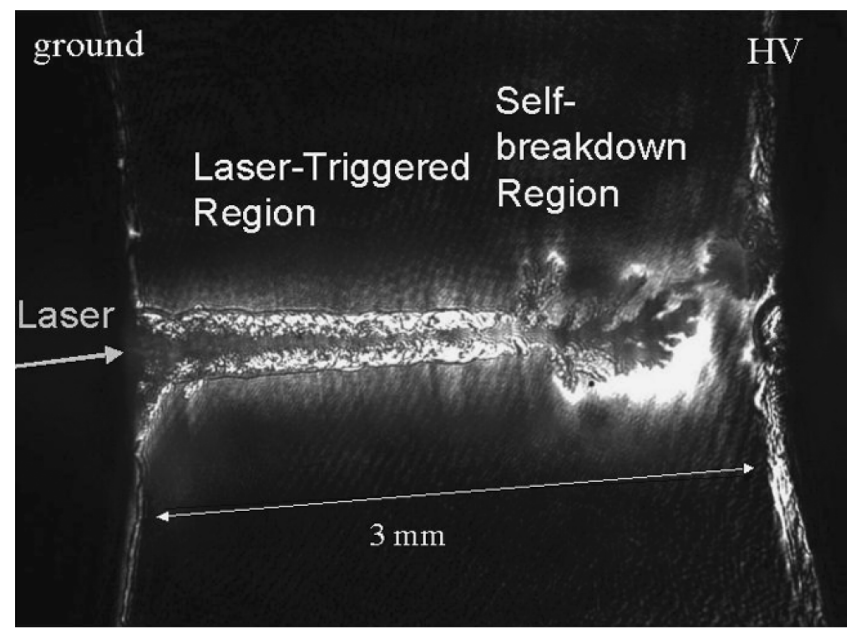

Figure 11. Time-resolved Schlieren photograph of laser-induced breakdown in a $170 \mathrm{kV}$ switch a few nanoseconds before breakdown [73].

\section{MATERIAL PROCESSING}

Pulsed power technologies are utilized for some material processes. Plasma-based ion implantation and deposition (PBII\&D or PBIID) is one of the modern technology employing pulsed power technique for surface treatment of complex shape materials. PBIID can now be considered a mature technology for surface modification and thin film deposition after pioneering work in the 1990s [80]. In this section, pulse power applications for material process are described focusing on the PBIID technologies. Other applications of the pulsed power technologies described in here are material ablation, surface heating (annealing) and new material synthesizing. Pulsed high-power lasers are employed to ablate solid materials as ion or neutral particle sources for new material synthesis and/or film depositions [81]. Pulsed high-power lasers and high-power microwaves are also used to heat material surfaces (annealing) [82]. Metal foil evaporation with pulsed large currents are used for synthesizing fine particles, ceramics joining, and plasma generation used as ion sources $[83,84]$. These technologies are also described in this section as pulsed power applications.

\subsection{PLASMA-BASED ION IMPLANTATION AND DEPOSITION}

A conventional ion source for surface modification is comprised of a plasma generator and a means for ion extraction and acceleration [85]. Typical ion beam systems are characterized by having a preferred direction, the direction of ion beam propagation. As a consequence, ion beam treatment, like ion implantation, is a line-of-sight process. This is wellsuited for planar substrates like wafers, but impractical for treatment of three-dimensional (3-D) objects because complicated substrate motion would be required to achieve uniformity.

Plasma-based ion implantation and deposition (PBIID) was originally developed as a revolutionary non line-of-sight process by incorporating a three-dimensionally shaped target (substrate) in the ion acceleration scheme itself, rather than utilizing conventional ion extraction. The object to be treated was immersed in the plasma, and became a part of the ion source in a more general sense by biasing. Ion acceleration occurs in a dynamically self-adjusting sheath that forms around the biased target surface $[80,86]$.

In the plasma-based ion implantation (PBII) technique, substrates are immersed directly in the plasma and biased negatively with high-voltage pulses. The plasma conforms to and surrounds the substrate, of which the whole surface is implanted at the same time. PBII eliminates the intermediate stages such as beam extraction, focusing, and scanning, as well as substrate or wafer manipulation. PBII has many advantages [80] such as high ion current density, relatively short processing time (e.g., minuets), high dose rate (e.g., $10^{14} \mathrm{~cm}^{-2} \mathrm{~s}^{-1}$ ), wide ion energy range (up to about $100 \mathrm{keV}$ ), large implant areas (100's of $\mathrm{cm}^{2}$ ) and treatment of 3-D work pieces with complex shapes, in comparison with conventional implantation.

The typical PBII system consists of a plasma chamber and negative bias pulse voltage generator as shown in Figure 12 [87]. Generally, plasmas are produced by direct current (dc) hot cathode (filaments), RF discharges sustained at $13.56 \mathrm{MHz}$, or electron cyclotron resonance (ECR) discharges at $2.45 \mathrm{GHz}$ [88]. In Figure 12, the plasma was produced utilizing distributed electron cyclotron resonance (DECR) system which consists of 24 magnet bars for multi-polar magnetic field confinement and ECR resonance. The plasma reactor is $60 \mathrm{~cm}$ in diameter and $70 \mathrm{~cm}$ in height. The negative high-voltage of 10's of $\mathrm{kV}$ is applied to the substrate holder to extract ions from plasmas.

Typical voltage and current waveforms of the substrate holder are shown in Figure 13 [87]. When a rectangular high-voltage negative pulse is applied to a conducting substrate immersed in plasma, an ion sheath develops around the substrate. The ions are accelerated towards the substrate surface, where they are implanted. According to physical timescales, three different phases can be distinguished [88]. First, when the bias voltage is supplied instantaneously, electrons are repelled on the timescale of the inverse electron plasma frequency exposing a matrix of ions which are too massive to respond quickly. This phenomenon is called an ion matrix sheath. Second, on the slower timescale of the inverse ion plasma frequency the ions in the matrix sheath are accelerated toward the substrate and the ion current density reaches a sharp maximum. Third, on a longer time scale, the sheath and current density evolve toward a steady-state configuration.

A rectangular high-voltage negative pulse is generated by employing a pulse transformer, a stacked Blumlein line, or a pulse forming network [89-91]. For example, the circuit layout of a pulser using solid-state technology is shown in 


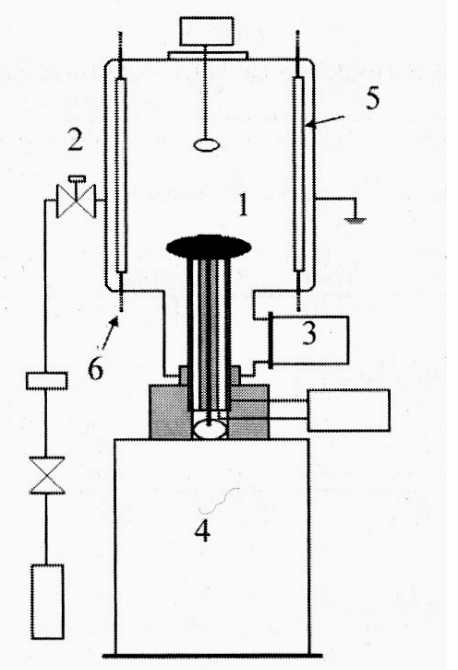

Figure 12. Schematic design of a PBII facility using a DECR plasma excitation. (1) High-voltage substrate holder. (2) Gas inlet. (3) Pumping (4) High-voltage pulse generator $100 \mathrm{kV}, 100 \mathrm{~A}$ using a pulse transformer. (5) 24 magnet bars for multipolar magnetic field confinement and ECR resonance condition. (6) 24 linear microwave applications running along the magnet bars. Plasma reactor is $60 \mathrm{~cm}$ in diameter and $70 \mathrm{~cm}$ high [87].

Figure 14 [89]. The circuit operation is based on a dc converter that uses an on-off switch to modulate the dc voltage. To increase the output voltage and provide isolation, the secondary windings of three step-up pulse transformers are connected in series. The modulator generated high-voltage negative pulses with an amplitude of about $4 \mathrm{kV}$, duration of 5 $\mu \mathrm{s}$, rise time of $1 \mu \mathrm{s}$, maximum current of $2.0 \mathrm{~A}$, and frequency of $5 \mathrm{kHz}$. Improvement in component lifetime is necessary to realize this system. Much work has focused on improvement of components made from stainless steel [92, 93], steel [94], titanium and aluminum alloy (Ti-6Al-4V) [94] and silicon wafer [95]. The kinetic energy of the ions is only needed to penetrate the surface layer of contamination or similar barrier, while the actual nitriding step is dominated by diffusion [94].

Ion implantation has a limited processing depth, and therefore coatings added to the portfolio of surface modifications which can be enhanced by the application of plasma-based processing. Typical classes of coating materials include metals, transition metal nitride, oxides, and various forms of diamond-like carbon.

Diamond-like carbon (DLC) materials are of great interested in applications where high hardness, chemical inertness and/or high temperature are required [96]. DLC can be deposited by various methods, for example, PBIID-type techniques [97-100]. PBIID is an especially effective technique for treating the inner surface of a cylinder (or tube), as shown in Figure 15 [100, 101]. Difficulty in the treatment of inner surfaces is the production of the plasma and the negative pulse bias of the inner surface [80].

There are also applications for biocompatible metals such as austenitic stainless steel, tantalum, niobium, cobalt chrome nickel alloys, titanium and titanium alloys [80, 103, 104]. Tian et al used oxygen PBII to increase bioactivity, wear resistance, and corrosion resistance of titanium alloy (Ti-6Al-4V) [102]. Wan et al. used PBIID to fabricate silicon-oxynitride (Si-N-O) film on silicon wafers to increase blood compatibility [103].

Efforts to increase the plasma density have been made and produce a decrease in the sheath thickness in proportion to the inverse of the square root of the plasma density [80];
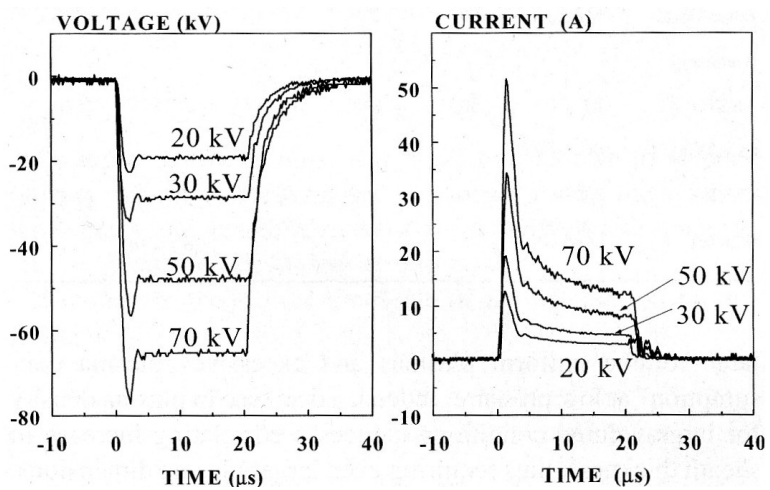

Figure 13. Typical voltage and current waveforms obtained with a $0.13 \mathrm{~Pa}$ nitrogen plasma using a $100 \mathrm{kV}, 100 \mathrm{~A}$ pulse transformer. Surface of the stainless steel substrate is $300 \mathrm{~cm}^{2}$ [87].

$$
l=\frac{2^{5 / 2} \varepsilon_{0} V_{0}^{3 / 4}}{3 \exp (-1 / 4) e^{1 / 4} n_{e}^{1 / 2}\left(k T_{e}\right)^{1 / 4}} \approx \lambda_{D e}\left(\frac{e V_{0}}{k T_{e}}\right)^{3 / 4}
$$

where $\mathrm{V}_{0}$ is the negative potential of the substrate during the pulse, $\mathrm{Te}$ is the electron temperature, $\mathrm{k}$ is Boltzmann constant, $\varepsilon_{0}$ is the permittivity of free space, $n_{\mathrm{e}}$ is the electron density, and $\lambda D_{e}$ the electron Debye length. Takeuchi et al used the theta pinch phenomena to increase plasma density [105]. High-density plasmas have the advantage not only of a thin sheath around the work piece, but also a high deposition rate of the fabricated film. Takaki et al used Lorenz force to accelerate an carbon plasma, produced using a shunting arc discharge scheme, toward the Si substrate holder as shown in Figure 16 [98]. This system achieved a deposition rate of 100 $\mathrm{nm} / \mathrm{min}$ for an carbon film on a silicon wafer [106].

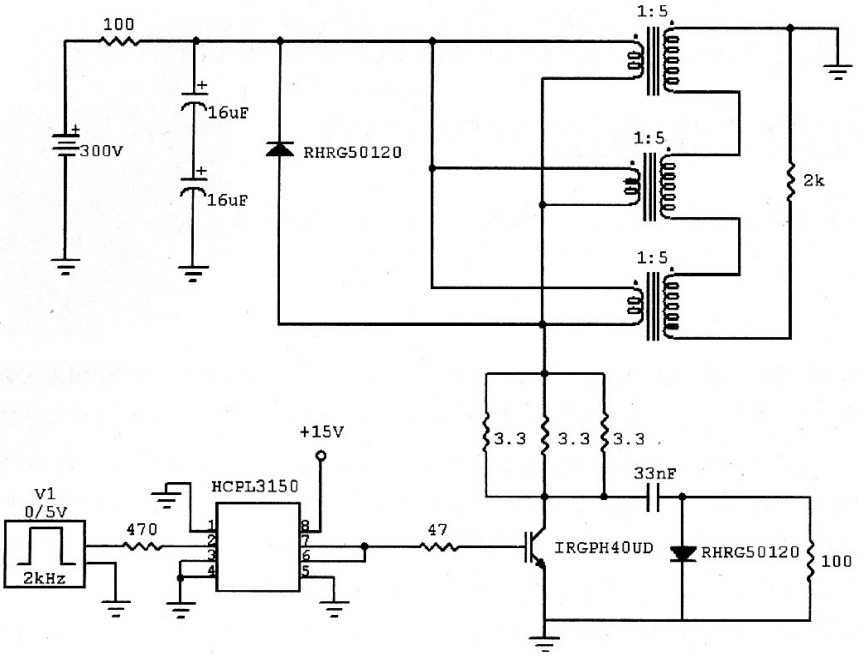

Figure 14. Circuit layout of a solid-state pulser [89]. 
Vacuum chamber
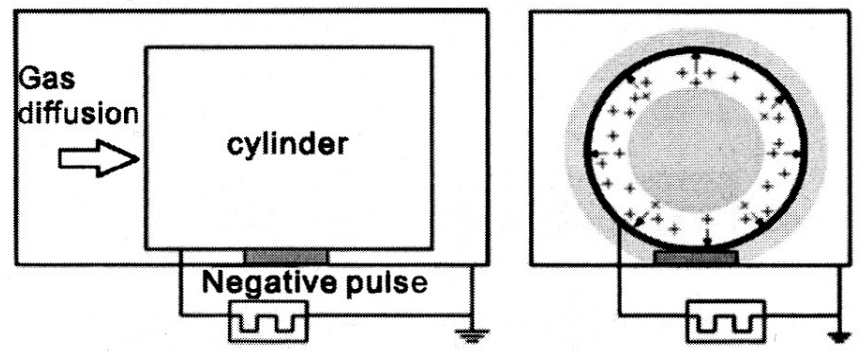

Figure 15. Schematic diagram of a PBIID system for inner surface modification of a cylinder tube [100].

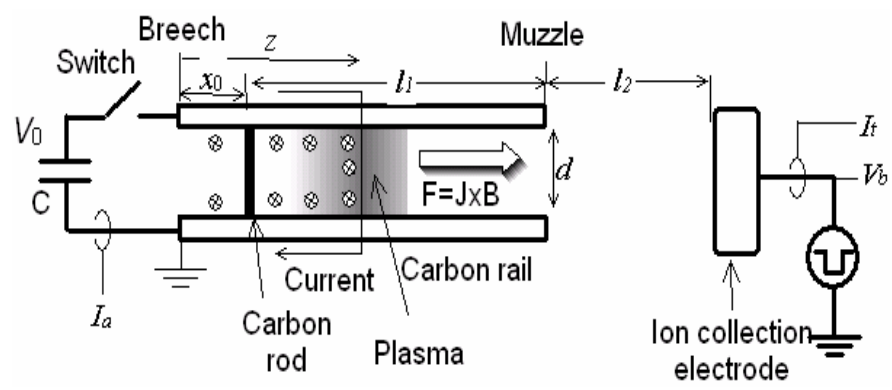

Figure 16. Schematic diagram of a magnetically driven carbon shunting arc system for PBIID [98].

\subsection{ION SOURCE FOR MATERIAL PROCESS}

Ion source research is a remarkably active area from the need for various ion beams for material processes. Most ion sources are extracted from plasmas generated by various methods. Laser ion sources (LIS) are based on plasmas produced by a high-power laser beam focused on a solid target [81, 107]. Vacuum arc ion sources have evolved over the past 20 years into a standard laboratory tool for production of high current metal ions [108]. An electron beam is also utilized to generate plasmas for material processing [109].

Laser ion sources (LIS) are capable of delivering highly charged ions with high intensity and can be used for direct ion implantation of materials in order to modify the surface properties such as hardness, roughness, electrical conductivity, and chemical reactivity. A typical LIS system for material application is shown in Figure 17 [110]. The high-power iodine laser of the Prague Asterix Laser System, emitting radiation with a $438 \mathrm{~nm}$ wavelength, $400 \mathrm{ps}$ pulse duration and about $250 \mathrm{~J}$ maximum pulse energy, was employed to irradiate a germanium target in vacuum. Energetic Ge ions emitted from the laser-produced plasma were directly implanted into $C$ substrates placed $30 \mathrm{~cm}$ from the target. The Ge implantation depth was analyzed to be about 150-750 nm [110].

A characteristic of a vacuum arc (cathodic-vacuum arc) ion source is the production of high current beams of metal ions. The metal plasma is produced by the vacuum arc discharge. Ion beams have been produced for over 50 solid metals of the periodic table, with ion energies of up to several hundred $\mathrm{keV}$ and beam currents up to several amps. The source is usually a repetitively operated electric pulse with a pulse width up to some milliseconds and duty cycles of $10 \%$ or more. The ions have low but multiple-ionized charge states. The mean charge state lies between 1 and 3, and the charge states can be increased in a number of different ways [108].

Since cathodic vacuum arc technology was used for modifying (coating) material surface by Thomas Edison in 1892 [111], the cathodic vacuum arc ion deposition technique has attracted great interest in the formation of various metal or alloy films, such as TiN, $\mathrm{ZrN}, \mathrm{CrN}$ and AlN [112, 113]. Recently, the cathodic vacuum arc is used to prepare magnesium-oxide $(\mathrm{MgOx})$ films for the protective layer of alternating-current plasma display panel (ac-PDP) [114]. For the preparation of $\mathrm{MgOx}$ films, $\mathrm{Mg}$ plate is employed as the target ablated by the cathodic vacuum arc in low pressure oxygen. The negative bias pulse voltage is applied on substrates for ion extraction as shown in Figure 18 [114].

A shunting arc discharge can be used as an ion source of metals and semi-metal materials, such as titanium, tungsten, silicon, and carbon, and is ignited without any trigger source at a wide range of gas pressures from vacuum to atmospheric pressure under identical discharge conditions $[98,115]$. The shunting arc is ignited or triggered by self-heating of the rod to increase the vapor pressure and/or to emit thermoelectrons around a rod, as shown in Figure 19. The particles evaporated from the surface of the rod, as shown in

Figures 19a and 19b, increased the local gas pressure and reduced the breakdown field level around the rod which was at a lower ambient gas pressure than the Paschen minimum breakdown point. The rod heated by a large current also works as an electron emitter. The emitted electrons are accelerated toward the chamber wall, colliding with the gas species to make ions under middle or high gas pressure circumstances. Takaki et al. prepared amorphous carbon (a-C) films with a high deposition rate $(100 \mathrm{~nm} / \mathrm{min})$ using a carbon shunting arc discharge as an ion source [116]. Yukimura et al. also prepared a-C films using a carbon shunting arc discharge in methane gas to control hydrogen content as shown in Figure 20 [117].

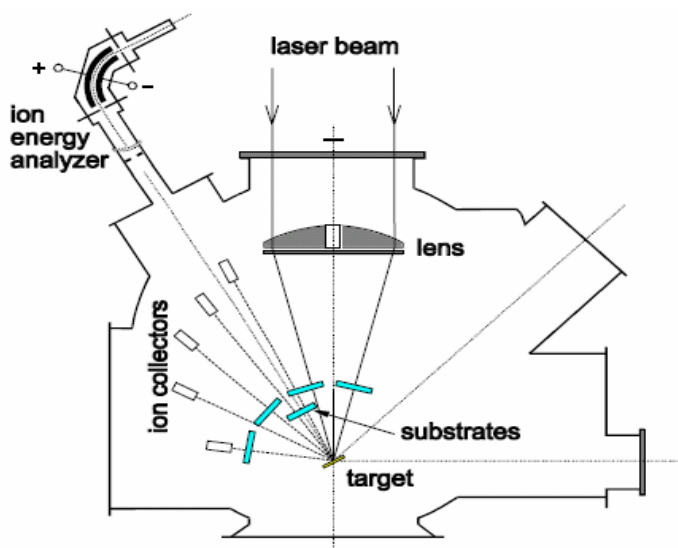

Figure 17. Schematic diagram of a laser ion source for implantation of Ge ions into C substrates [110]. 


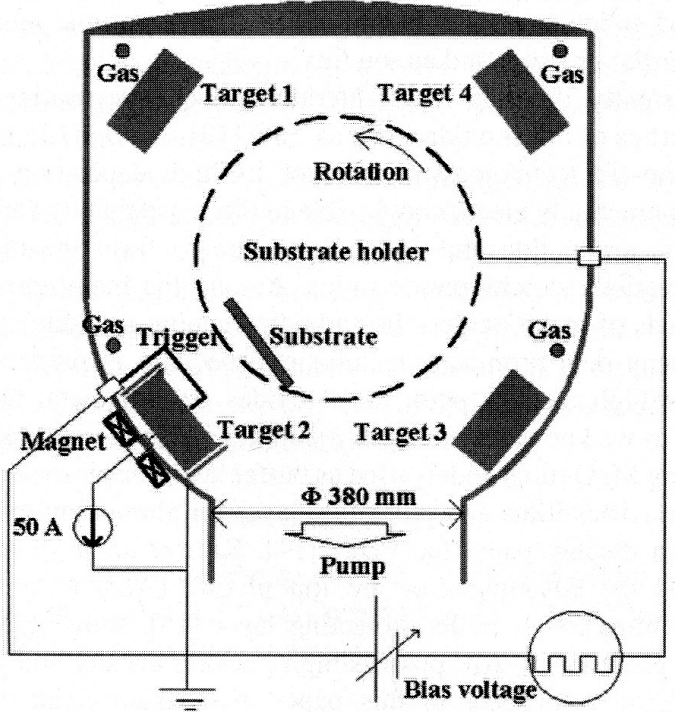

Figure 18. Schematic diagram of a cathodic vacuum arc ion source for depositing $\mathrm{MgOx}$ films [114].

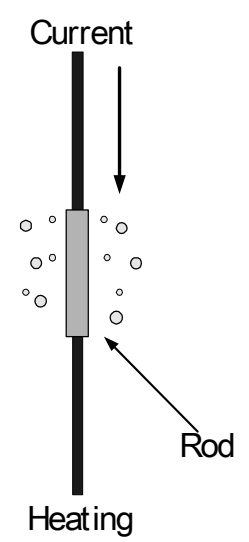

(a)

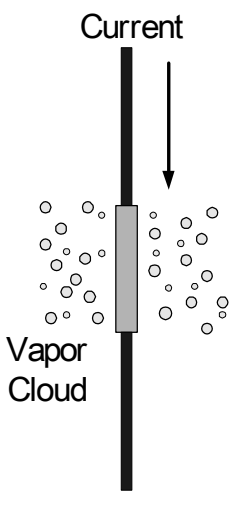

(b)

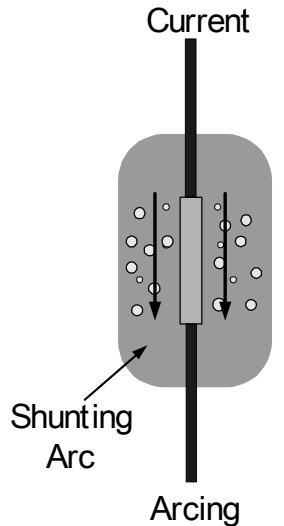

(c)

\section{Time}

Figure 19. Schematics of the shunting arc ignition process [98].

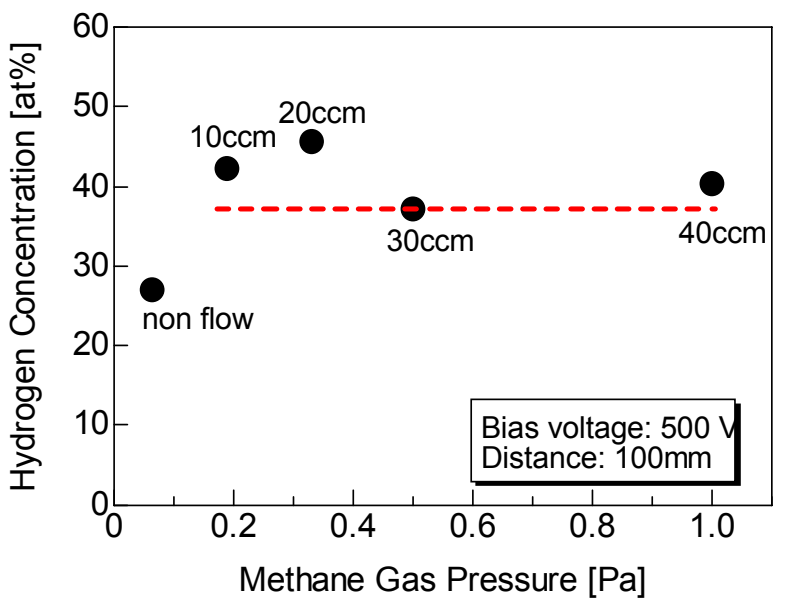

Figure 20. Hydrogen contaminating concentration in the deposited carbon film as a function of ambient methane gas pressure [117].

\subsection{OTHER APPLICATIONS}

Pulsed power technologies can be used in other material processes, such as surface heating (annealing) by laser [118] or microwave irradiation, synthesis of nanocomposite powders [83], and joining of solid materials [119].

Energetic beams such as lasers are powerful tools to modify the surface of materials. Various types of laser such as ruby-, Nd:YAG-, Ti:sapphire-, excimer XeCl-, and $\mathrm{CO}_{2}$-laser have been employed for surface modification. For example, the surface temperature of TiN rises to $6,000 \mathrm{~K}$ within $20 \mathrm{~ns}$ by irradiation using a $\mathrm{XeCl}$ laser $\left(2.4 \mathrm{~J} / \mathrm{cm}^{2}\right)$ [118]. The decomposition temperature of a TiN coating is around 3,200 K, therefore, reform and ablation occur in a short time period.

High power micro- or millimeter-wave beam can also be employed to heat a material surface. This method is especially effective on dielectric materials, e.g., ceramics. Bruce et al. employed a high-power $83 \mathrm{GHz}$ millimeterwave beam for joining ceramics tubes [119]. This method exploits the use of the beam-forming capability of an 83$\mathrm{GHz}$ gyrotron-based system allowing energy deposition in a narrow region surrounding the joint area with minimal heating of the metal fixture. Three pieces of high purity aluminum oxide $(99.5 \%$ Alumina) joined with reactive glass braze are shown for demonstration in Figure 21. The shear strength of the joint was found to be $121 \mathrm{MPa}$, which is comparable to the strength of the ceramics themselves [119].

Exploding (fusing) metallic foil or wire can be used for nanocomposite particles synthesis, and joining dielectric materials such as ceramics. Takaki et al. used $50 \mu \mathrm{m}$ titanium foils for joining alumina tiles. The shear strength of the joined alumina tiles increased with increasing input energy to the titanium foil as shown in Figure 22 [84]. Lee et al. used aluminum and zirconium exploding wires in oxygen for the synthesis of zirconia-alumina nanocomposite powders [83]. The produced powders showed a spherical morphology with less agglomeration.

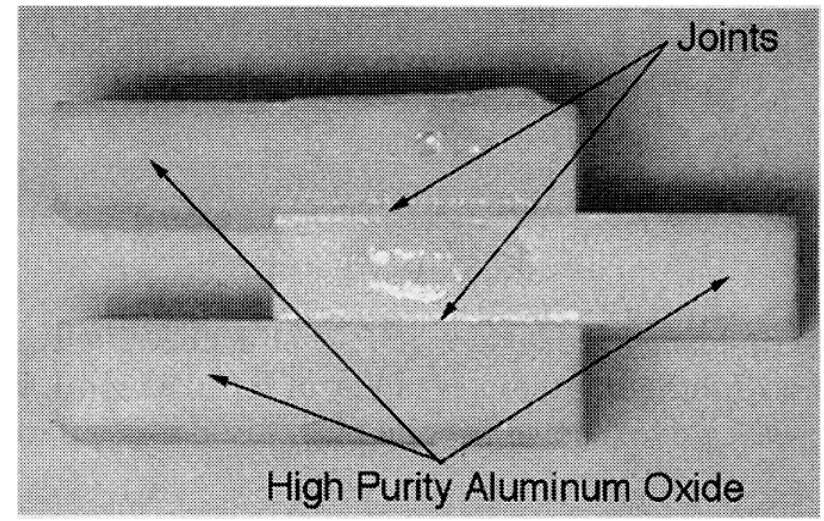

Figure 21. Joined alumina tiles using high-power millimeter-wave beam irradiation [119]. 




Figure 22. Shear strength as a function of total input energy for various foil widths at $50 \mu \mathrm{m}$ in foil thickness [84].

\section{SUMMARY}

This review has concentrated on industrial applications of pulsed power. Repetitively operated pulsed power generators with a moderate peak power have been developed using semiconductor and magnetic switches for industrial applications. These generators are compact, reliable, low maintenance, and have high reproducibility. Many studies of industrial applications of pulsed power, such as food processing, medical treatment, water treatment, exhaust gas treatment, ozone generation, engine ignition, ion implantation and others, came about with development of such a pulse power generator. Industrial applications of pulsed power are classified as applications using biological effects, using pulsed streamer discharges in gases, using pulsed discharges in liquid or liquid-mixture, and material processing. Those developed over the past two years have been reviewed.

\section{REFERENCES}

[1] W.C. Nunnally, "Critical component requirements for compact pulse power architectures", IEEE Trans. Plasma Sci., Vol. 33, pp. 1262-1267, 2005.

[2] S. Katsuki, H. Imamura, S. Akiyoshi, T. Namihira, T. Sakugawa, H. Akiyama, K. Tomita and K. Uchino, "Characterization of Z-Pinch Plasmas for EUV Light Sources", 15th IEEE Pulsed Power Conf., pp. 864-867, 2005.

[3] T. Sakugawa, T. Yamaguchi, K. Yamamoto T. Kiyan, T. Namihira, S. Katsuki and H. Akiyama, "All Solid State Pulsed Power System for Water Discharge", 15th IEEE Pulsed Power Conf., pp. 1057-1060, 2005.

[4] C. Huang, P. Melcher, G. Ferguson and R. Ness, "Loss Estimation of Capacitor in High Rep-Rate Pulsed Power System", 15th IEEE Pulsed Power Conf., pp. 1077-1080, 2005.

[5] R. Burdt, K. F. McDonald, R. D. Curry, B. Huhman, P. Melcher, R. Ness, C. Huang and G. Ferguson, "Evaluation of Nanocrystalline Materials, Amorphous Alloys and Ferrites for Repetitive-Magnetic Pulse Compression Application", 15th IEEE Pulsed Power Conf., pp. 843-847, 2005.

[6] A. Pokryvailo, M. Wolf, Y. Yankelevich, S. Wald, L. R. Grabowski, E. M. van Veldhuizen, Wijnand R. Rutgers, M. Reiser, B. Glocker, T. Eckhardt, P. Kempenaers and A. Welleman, "High-Power Pulsed Corona for Treatment of Pollutants in Heterogeneous Media", IEEE Trans. Plasma Sci., Vol. 34, pp.1731-1743, 2006.

[7] G.J.J. Winands, K. Yan, A.J.M. Pemen, S.A. Nair, Z. Liu and E.J.M. van Heesch, "An Industrial Streamer Corona Plasma System for Gas Cleaning", IEEE Trans. Plasma Sci., Vol. 34, pp.2426-2433, 2006.
[8] W. Hartmann, T. Hammer, T. Kishimoto, M. Romheld and A. Safitri, "Ozone Generation in a Wire-Plate Pulsed Corona Plasma Reactor", 15th IEEE Pulsed Power Conf., pp. 856-859, 2005.

[9] J. Choi, T. Yamaguchi, K. Yamamoto, T. Namihira, T. Sakugawa, S. Katsuki and H. Akiyama, "Feasibility Studies of EMTP Simulation for the Design of the Pulsed-Power Generator Using MPC and BPFN for Water Treatments", IEEE Trans. Plasma Sci., Vol. 34, pp.1744-1750, 2006.

[10] A. Pokryvailo, M. Wolf, Y. Yankelevich, S. Wald, L.R. Grabowski, E.M.Van Veldhuizen, W.R. Rutgers, M. Reiser, B. Glocker, T. Eckhardt, P. Kempenaers and A. Welleman, "High-Power Pulsed Corona for Treatment of Pollutants in Heterogeneous Media", IEEE Trans. Plasma Sci., Vol. 34, pp.1731-1743, 2006.

[11] R. Narsetti, R.D. Curry, K.F. McDonald, L.M. Nichol and T. Clevenger, "Application of Pulsed Electric Fields and Magnetic Pulse Compressor Technology for Water Sterilization", 15th IEEE Pulsed Power Conf., pp. 1282-1285, 2005.

[12] J. Kolb, W. Frey, J.A. White, R.O. Price, P.F. Blackmore, S.J. Beebe, R.P. Joshi and K.H. Schoenbach "Measurements of The Transmembrane Voltage in Biological Cells for Nanosecond Pulsed Electric Field Exposures", 15th IEEE Pulsed Power Conf., pp. 1286-1289, 2005.

[13] E.Y. Shcolnikov, S.P. Maslennikov, N.N. Netchaev and D.V. Petrov, "Atmospheric pulsed Diffuse discharge in highly on-uniform field to be used for sterilization and decontamination", 15th IEEE Pulsed Power Conf., pp.1421-1424, 2005.

[14] P. Baroch, T. Takeda, M. Oda, N. Saito and O. Takai, "Degradation of bacteria using pulse plasma discharge in liquid medium", 27th Power Modulator Symposium, pp.482-485, 2006.

[15] Z. Li, S. Sakai, C. Yamada, D. Wang, S. Chung, X. Lin, T. Namihira, S. Katsuki and H. Akiyama, "The effect of pulsed streamer like discharge on cyanobacteria cells", IEEE Trans. Plasma Sci., Vol. 34, pp. 1719-1724, 2006.

[16] R. Zhang, L. Wang, Y. Wu, Z. Guan and Z. Jia, "Bacterial decontamination of water by bipolar pulsed discharge in a gas-liquid-solid three-phase discharge reactor", IEEE Trans. Plasma Sci., Vol. 34, pp. 1370-1374, 2006.

[17] A.H. El-Hag, S.H. Jayaram and M.W. Griffiths, "Inactivation of naturally grown microorganisms in orange juice using pulsed electric fields", IEEE Trans. Plasma Sci., Vol. 34, pp. 1413-1415, 2006.

[18] M. Sack, C. Schultheiss and H. Bluhm, "Triggered Marx generators for the industrial-scale electroporation of sugar beets", IEEE Trans. Industry Applications, Vol. 41, pp. 707-714, 2005.

[19] S. Tsukamoto, K. Yamamoto, H. Kudoh, S. Ohga and H. Akiyama, "Development of an automatic electrical stimulator to mushroom sawdust pots", 15th IEEE Pulsed Power Conf., pp.1437-1440, 2005.

[20] Y. Sun, P.T. Vernier, M. Behrend, L. Marcu and M.A. Gundersen, "Electrode microchamber for noninvasive perturbation of mammalian cells with nanosecond pulsed electric fields", IEEE Trans. Nanobioscience, Vol.4, pp.277-283, 2005.

[21] R. Nuccitelli, U. Pliquett, X. Chen, W. Ford, R. J. Swanson, S. J. Beebe, J. F. Kolb and K. H. Schoenbach, "Nanosecond pulsed electric fields cause melanomas to self-destruct", Biochem. Biophys. Res. Comm., Vol. 343, pp. 351-360, 2006.

[22] N. Nomura, S. Abe, I. Uchida, K. Abe, H. Koga, S. Katsuki, T. Namihira, H. Akiyama, H. Takano and S. Abe, "Response of biological cells exposed on burst RF fields", 15th IEEE Pulsed Power Conf., pp.1437-1440, 2005.

[23] R. Hackam and H. Akiyama, "Air pollution control by electrical discharges", IEEE Trans. Diel. Elect. Insul., Vol.7, pp.654-683, 2000.

[24] M.A. Malik, Y. Minamitani and K.H. Schoenbach, "Comparison of catalytic activity of aluminum oxide and silica gel for decomposition of volatile organic compounds (VOCs) in a plasmacatalytic reactor", IEEE Trans. on Plasma Sci., Vol.33, pp.50-56, 2005.

[25] T. Oda, T. Takahashi and K. Yamaji, "Nonthermal plasma processing for dilute VOCs decompoition", IEEE Trans. Indust. Appl., Vol.38, pp.873-878, 2002.

[26] K. Urashima and J. Chang, "Removal of volatile organic compounds from air streams and industrial flue gases by non-thermal plasma technology", IEEE Trans. Diel. Elect. Insul., Vol.7, pp.602-614, 2000.

[27] T. Kimura, Y. Hattori and A. Oda, "Ozone production efficiency of atmospheric dielectric barrier discharge of oxygen using time-modulated power supply", Japan J. Appl. Phys., Vol.43, No.11A, pp.7689-7692, 2004.

[28] H. Ahn, N. Hayashi, S. Ihara and C. Yamabe, "Ozone generation characteristics by superimposed discharge in oxygen-fed ozonizer", Japan J. Appl. Phys., Vol.42, pp.6578-6583, 2003. 
[29] G. Imada and K. Yatsui, "Characteristics of treatment of diesel flue gas by irradiation of pulsed intense relativistic electron beam", IEEE Trans. Plasma Sci., Vol.34, pp.88-93, 2006.

[30] R. Hackam and H. Akiyama, "Application of pulsed power for the removal of nitrogen oxides from plluted air", IEEE Elect. Insul. Magazine, Vol.17, No.5, pp.8-13, 2001.

[31] W. Wang, Z. Zhao, F. Liu and S. Wang, "Study of NO/NOX removal from flue gas contained fly ash and water vapor by pulsed corona discharge", J. Electrostatics, Vol.63, pp.155-164, 2005.

[32] K. Aritoshi, M. Fujiwara and M. Ishida, "Decline of NOX reducing removal ability with the effect of $\mathrm{CO}_{2}$ on $\mathrm{NO}_{\mathrm{X}}$ treatment using streamer discharge", Japan J. Appl. Phys., Vol.41, pp.7522-7528, 2002.

[33] E.A. Eilimonova, Y.H. Kim, S.H. Hong and Y. Song, "Multiparametric investigation on $\mathrm{NO}_{\mathrm{X}}$ removal from simulated diesel exhaust with hydrocarbons by pulsed corona discharge", J. Phys. D: Appl. Phys., Vol.35, pp.2795-2807, 2002.

[34] B.M. Penetrante, M.C. Hsiao, B.T . Merritt, G.E. Vogtlin, P.H. Wallman, M. Neiger, O. Wolf, T. Hammer and S. Broer, "Pulsed corona and dielectric-barrier discharge processing of NO in $\mathrm{N}_{2}$ ", Appl. Phys. Letter, Vol.68, pp.3718-3721, 1996.

[35] M. Rong, X. Yuan and X. Wang, "Removal of sulfur dioxide in domestic air by non-thermal plasma", XV Int. Conf. on Gas Discharges and their Appl., pp.761$764,2004$.

[36] Y. Wu, J. Li, N. Wang, G. Li and D. Xu, "Study on increasing the $\mathrm{SO}_{2}$ removal efficiency with the radicals produced by $\mathrm{H}_{2} \mathrm{O}$ in pulse discharge plasma process", Japan J. Appl. Phys., Vol.40, No.8A, pp.L838-L840, 2001.

[37] H.H. Kim, C.Wu, Y. Kinoshita, K. Takashima, S. Katsura and A. Mizuno, "The influence of reaction conditions on $\mathrm{SO}_{2}$ oxidation in a discharge plasma reactor", IEEE Trans. Indust. Appl., Vol.37, pp.480-487, 2001.

[38] Y. Nakagawa, A. Kohchi and T. Nishitani, "Deoxidization of carbon dioxide by pulse power discharge", Japan J. Appl. Phys., Vol.32, No.10B, pp.L1568L1570, 1993.

[39] V. Demidiouk and J.O. Chae, "Decomposition of volatile organic compounds in plasma-catalytic system", IEEE Trans. Plasma Sci., Vol.33, pp.157-161, 2005.

[40] J.B. Gajewski, T. Maczka, D. N. Wozny, J. Fleszynski and R. Pozniak, "Some hydrocarbon derivative compounds decomposition using the HV impulse discharge", J. Electrostatics, Vol.62, pp.269-275, 2004.

[41] V. I. Golota, L. M. Zavada, B. B. Kadolin, I.A. Paschenko, S. G. Pugach, G.V. Taran and A.V. Yakoclev, "Pulsed discharge for ozone synyhesis", XV Int. Conf. on Gas Discharges and their Appl., pp.750-756, 2004.

[42] M. Simek and M. Clupek, "Efficiency of ozone production by pulsed corona discharge in synthetic air”, J. Phys. D: Appl. Phys., Vol.35, pp.1171-1175, 2002.

[43] W.J.M. Samaranayake, Y. Miyahara, T. Namihira, S. Katsuki, R. Hackam and H. Akiyama, "Pulsed power production of ozone in $\mathrm{O}_{2} / \mathrm{N}_{2}$ in a coaxial reactor without dielectric layer", IEEE Trans. Diel. Elect. Insul., Vol.8, No.5, pp.826831, 2001.

[44] W.J.M. Samaranayake, Y. Miyahara, T. Namihira, S. Katsuki, T. Sakugawa, R. Hackam and H. Akiyama, "Pulsed power production of ozone using nonthermal gas discharges", IEEE Elect. Insul., Magazine, Vol.17, No.4, pp.17-25, 2001.

[45] T. Namihira, K. Shinozaki, S. Katsuki, H. Akiyama, R. Hackam and T, Sakugawa, "Characteristics of ozonizer using pulsed power", 13th IEEE Pulsed Power Conf., Vol.2, pp.1090-1093, 2001.

[46] W.J.M. Samaranayake, Y. Miyahara, T. Namihira. S. Katsuki, T. Sakugawa, R. Hackam and H. Akiyama, "Pulsed streamer discharge characteristics of ozone production in dry air”, IEEE Trans. Diel. Elect. Insul., Vol.7, pp.254-260, 2000.

[47] T. Namihira, S. Tsukamoto, D. Wang, S. Katsuki, R. Hackam, H. Akiyama, Y. Uchida and $\mathrm{M}$. Koike, "Improvement of $\mathrm{NO}_{\mathrm{x}}$ removal efficiency using short width pulsed power", IEEE Trans. Plasma Sci., Vol.28, pp.434-442, 2000.

[48] D. Wang, M. Jikuya, S. Yoshida, T. Namihira, S. Katsuki and H. Akiyama, "Observation of pulsed streamer discharges in atmospheric air using submicrosecond pulse generator", 15th IEEE Pulsed Power Conf., pp.997-1000, 2005.

[49] T. Namihira, D. Wang, S. Katsuki, R. Hackam and H. Akiyama, "Propagation velocity of pulsed streamer discharges in atmospheric air", IEEE Trans. Plasma Sci., Vol.31, pp.1091-1094, 2003.

[50] D. Wang, T. Namihira, S. Katsuki and H. Akiyama, "Ultra-short pulse generator for environmental control", 15th Int. Conf. on Gas Discharges and Their Appl., Vol.2, pp.709-712, 2004.

[51] D. Wang, S. Yoshida, M. Jikuya, T. Namihira, S. Katsuki and H. Akiyama, "Observation of pulsed streamer discharges in atmospheric air using nanosecond pulse generator", 15th IEEE Pulsed Power Conf., pp.1001-1004, 2005.
[52] T. Namihira, D. Wang and H. Akiyama, "Propagation velocity of ns pulsed streamer discharge in atmospheric air", 1st Euro-Asian pulsed power conf., Thu-O 20, 2006.

[53] Y.S. Mok, H.W. Lee and Y.J. Hyun, "Flue gas treatment using pulsed corona discharge generated by magnetic pulse compression modulator", J. Electrostatics, Vol. 53, pp.195-208, 2001.

[54] J. Chung, M. Cho, B. Son, Y. Mok and W. Namkung, "Study on reduction of energy consumption in pulsed corona discharge process for $\mathrm{NO}_{\mathrm{X}}$ removal", Plasma Chemistry and Plasma Processing, Vol. 20, No. 4, pp.495$509,2000$.

[55] Y.S. Mok and I. Nam, "Removal of nitric oxide in a pulsed corona discharge reactor", Chemical Engineering and Technology, Vol. 22, pp.527-532, 1999.

[56] T. Namihira, H. Hori, D. Wang, S. Tsukamoto, S. Katsuki, H. Akiyama, M. Shimizu and K. Yokoyama, "Effect of $\mathrm{NH}_{3}$ on NOX removal using pulsed power", XXV Int. Conf. on Phenomena in Ionized Gases, Vol. 4, p.137, 2001.

[57] B. M. Penetrante, R. M. Brusasco, B. T. Merritt and G. E. Vogtlin, "Environmental applications of low-temperature plasmas", Pure and Appl. Chemistry, Vol. 71, pp.1829-1835, 1999.

[58] Y.S. Mok, M. Dors and J. Mizerazcyk, "Effect of reaction temperature on $\mathrm{NO}_{\mathrm{X}}$ removal and formation of ammonium nitrate in nonthermal plasma process combined with selective catalytic reduction", IEEE Trans. Plasma Sci., Vol. 32, pp.799-807, 2004.

[59] T. Namihira, T. Yamaguchi, K. Yamamoto, J. Choi, T. Kiyan, T. Sakugawa, S. Katsuki and H. Akiyama, "Characteristics of Pulsed Discharge Plasma in Water", 15th IEEE Pulsed Power Conf., pp.1013-1016, 2005.

[60] K. Kadowaki, S. Nishimoto and I. Kitani, "Space charge effect for streamer initiation and propagation in water subjected to reciprocal traveling wave voltage pulse", IEEE Trans. Diel. Elect. Insul., Vol.13, pp.484-491, 2006.

[61] J. Choi, T. Yamaguchi, K. Yamamoto, T. Namihira, T. Sakugawa, S. Katsuki and H. Akiyama, "Feasibility Studies of EMTP Simulation for the Design of the Pulsed-Power Generator Using MPC and BPFN for Water Treatments", IEEE Trans. Plasma Sci., Vol.34, pp.1744-1750, 2006.

[62] Y. Minamitani, S. Shoji, Y. Ohba and Y. Higashiyama, "Decomposition of Dye in Water Solution by Pulsed Power Discharge in a Water Droplets Spray", 15th IEEE Pulsed Power Conf., pp.1009-1012, 2005.

[63] A. Pokryvailo, M. Wolf, Y. Yankelevich, S. Wald, L. R. Grabowski, E. V.M. Van Veldhuizen, W.R. Rutgers, M. Reiser, B. Glocker, T. Eckhardt, P. Kempenaers and A. Welleman, "High-Power Pulsed Corona for Treatment of Pollutants in Heterogeneous Media", IEEE Trans. Plasma Sci., Vol.34, pp.1731-1743, 2006.

[64] M.P. Gaudreau, T.J. Hawkey, J.E. Petry and M.A. Kempkes, "Solid-State Power Systems for Pulsed Electric Field (PEF) Processing", 15th IEEE Pulsed Power Conf., pp.1013-1016, 2005.

[65] J.W. Mackersie, I.V. Timoshkin and S.J. MacGregor, "Generation of highpower ultrasound by spark discharges in water", IEEE Trans. Plasma Sci., Vol.33, pp.1715-1724, 2005.

[66] P. Sunka, V. Stelmashuk, V. Babicky, M. Clupek1, J. Benes, P. Pouckova, J. Kaspar and M. Bodnar, "Generation of Two Successive Shock Waves Focused to a Common Focal Point", 15th IEEE Pulsed Power Conf., pp.1433-1436, 2005.

[67] F. Wang, J. B. Liu, J. Sinibaldi, C. Brophy, A. Kuthi, C. Jiang, P. Ronney and M. A. Gundersen, "Transient plasma ignition of quiescent and flowing air/fuel mixtures", IEEE Trans. Plasma Sci., Vol.33, pp.844-849, 2005.

[68] D.A. Wetz, K.P. Truman, J.J. Mankowski and M. Kristiansen, "The Impact of Surface Conditioning and Area on the Pulsed Breakdown Strength of Water", IEEE Trans. Plasma Sci., Vol.33, pp.1161-1169, 2005.

[69] D.A. Wetz, J.J. Mankowski, J.C. Dickens and M. Kristiansen, "The Impact of Field Enhancements and Charge Injection on the Pulsed Breakdown Strength of Water", IEEE Trans. Plasma Sci., Vol.34, pp.1670-1679, 2006.

[70] X. Lu, J. F. Kolb, S. Xiao, M. Laroussi, K. H. Schoenbach and E. Schamiloglu, "Dielectric Strength of Sub-Millimeter Water Gaps Subjected to Microsecond and Sub-Microsecond Voltage Pulses", 15th IEEE Pulsed Power Conf., pp.600-603, 2005.

[71] J. Qian, R. P. Joshi, J. F. Kolb, K. H. Schoenbach, J. Dickens, A. Neuber, M. Cevallos, H. Krompholz, E. Schamiloglu and J. Gaudet, "Simulation Studies of Liquid Water Breakdown by a Sub-Microsecond Pulse", 15th IEEE Pulsed Power Conf., pp.738-741, 2005.

[72] B. Cassany and L. Voisin, "Reproducibility Improvement on High Voltage Self-break Water Switches", 15th IEEE Pulsed Power Conf., pp.604-607, 2005. 
[73] J.R. Woodworth , D. Chalenski, G.S. Sarkisov and J.R. Blickem, "170-kV Laser-Triggered Water Switch Experiments", IEEE Trans. Plasma Sci., Vol.33, pp.2051-2059, 2005.

[74] J. Qian, R.P. Joshi, K.H. Schoenbach, J.R. Woodworth and G.S. Sarkisov, "Model Analysis of Self- and Laser-Triggered Electrical Breakdown of Liquid Water for Pulsed-Power Applications", IEEE Trans. Plasma Sci., Vol.34, pp.1680-1691, 2006.

[75] S. Xiao, J. F. Kolb, X. P. Lu, M. Laroussi, R. P. Joshi, K. H. Schoenbach and E. Schamiloglu, "Electrical Breakdown and Dielectric Recovery of Water and Propylene Carbonate", 15th IEEE Pulsed Power Conf., pp.742-745, 2005.

[76] S. Xiao, J. F. Kolb, M. A. Malik, X. Lu, M. Laroussi, R. P. Joshi, E. Schamiloglu and K. H. Schoenbach, "Electrical Breakdown and Dielectric Recovery of Propylene Carbonate", IEEE Trans. Plasma Sci., Vol.34, pp.1653-1661, 2006.

[77] L. K. Heffernan, R. D. Curry and K. F. McDonald, "A Fast, 3 MV Marx Generator for Megavolt Oil Switch Testing with an Integrated Abramyan Network Design", 15th IEEE Pulsed Power Conf., pp.596$599,2005$.

[78] P. Norgard, R.D. Curry, R. Burdt, R. Cravey, G. Anderson and S. Heidger, "A High Pressure Flowing Oil Switch for Gigawatt, Repetitive Applications", 15th IEEE Pulsed Power Conf., pp.1180$1183,2005$.

[79] P. Norgard, R. D. Curry and R. Sears, "Poly-\$alpha\$Olefin Synthetic Oil: A New Paradigm in Repetitive High-Pressure Oil Switches", IEEE Trans. Plasma Sci., Vol.34, pp.1662-1669, 2006

[80] J. Pelletier and A. Anders, "Plasma-based ion implantation and deposition: a review of physics, technology, and applications", IEEE Trans. Plasma Sci., Vol. 33, pp. 1944-1959, 2005.

[81] B. Sharkov and R. Scrivens, "Laser ion sources", IEEE Trans. Plasma Sci., Vol. 33, pp. 1778- 1785, 2005.

[82] X. P. Zhu, M. K. Lei and T. C. Ma, "Surface morphology of titanium irradiated by high-intensity pulsed ion beam", Nucl. Instrum. Methods Phys. Res. B, Vol. 211, pp. 69-79, 2003.

[83] P.Y. Lee, H. Suematsu, W. Jiang, K. Yatsui and K Niihara, " Synthesis of $\mathrm{Al}_{2} \mathrm{O}_{3}-\mathrm{ZrO}_{2}$ Nanocomposite Powders by Pulsed Wire Discharge ", IEEE Trans. Plasma Sci., Vol. 34, pp. 1190- 1194, 2006.

[84] K. Takaki, Y. Mikami, M. Itagaki, S. Mukaigawa, T. Fujiwara and S.Nakamura, "Influence of Metal Foil Width on Bonding Strength in Capacitor Discharge Ceramics Joining", IEEE Trans. Plasma Sci., Vol. 34, pp. 1709-1714, 2006

[85] I.G. Brown, Ed., The physics and Technology of Ion Sources, New York: Wiley, 1989.

[86] J.R. Conrad, "Plasma source ion implantation: a new approach to ion beam modification of materials", Matter. Sci. Eng., Vol. A116, pp. 197-203, 1989.

[87] F. Le Coeur, Y. Arnal, R.R. Burke, O. Lesaint and J. Pelletier, "Ion implantation based on the uniform distributed plasma ", Surf. Coat. Technol., Vol. 93, pp. 265-268, 1997.

[88] A. Anders, " Plasma and ion sources in large area coating: A review ", Surf. Coat. Technol., Vol. 200, pp. 1893-1906, 2005.

[89] J.O. Rossi, J.J. Barroso, M. Ueda and G. Da Silva, "A 4-kV/2-A/5$\mathrm{kHz}$ Compact Modulator for Nitrogen Plasma Ion Implantation", IEEE Trans. Plasma Sci., Vol. 34, pp. 1757- 1765, 2006.

[90] J.O. Rossi and M. Ueda, "A $100 \mathrm{kV} / 200$ A Blumlein Pulser for HighEnergy Plasma Implantation", IEEE Trans. Plasma Sci., Vol. 34, pp. 1766-1770, 2006.

[91] J.O. Rossii, J.J. Barros and M. Ueda, "Modeling of Wound Coaxial Blumlein Pulsers", IEEE Trans. Plasma Sci., Vol. 34, pp. 1846-1852, 2006.

[92] D. Manova, I.-M. Eichentopf, D. Hirsch, S. Mandl, H. Neumann and B.Rauschenbach, "Influence of Microstructure on Nitriding Properties of Stainless Steel", IEEE Trans. Plasma Sci., Vol. 34, pp. 1136-1140, 2006.

[93] A. Garamoon, U.M. Rashed, A. Abouelela, M.A. Eissa, A.H. Saudi, D.M. El-Zeer and F. El-Hossary", Hydrogen Effect on Nitriding Process of 304L Austenitic Stainless Steel", IEEE Trans. Plasma Sci., Vol. 34, pp. 1066- 1073, 2006.
[94] X. Ma, S. Xu and G. Tang, "Study on Properties of M50 Steel Implanted With Nitrogen by Plasma-Based Ion Implantation at Elevated Temperatures", IEEE Trans. Plasma Sci., Vol. 34, pp. 12041208,2006

[95] M. Ueda, H. Reuther, A.F. Beloto, C. Kuranaga and E. Abramof, "Annealing Effects on Silicon Oxynitride Layer Synthesized by N Plasma Immersion Ion Implantation", IEEE Trans. Plasma Sci., Vol. 34, pp. 1080- 1083, 2006.

[96] J. Robertson, "Diamond-like amorphous carbon", Mater. Sci. Eng. R., Vol. 37, pp. 129-281, 2002.

[97] C.C. Klepper, E.P. Carlson, R.C. Hazelton, E.J. Yadlowsky, B. Feng, M.A. Taher and H.M Meyer, "H $\alpha$ as a feedback control sensor for reactive sputter deposition of nano-structured, diamond-like carbon coatings", IEEE Trans. Plasma Sci., Vol. 33, pp. 799-807, 2005.

[98] K. Takaki, O. Kumagai, S. Mukaigawa, T. Fujiwara and K. Yukimura, "Ion Extraction From Magnetically Driven Carbon Shunting Arc Plasma", IEEE Trans. Plasma Sci., Vol. 34, pp. 1209-1215, 2006.

[99] Y. Oka, M. Nishijima, K. Hiraga and M. Yatsuzuka, "Effect of Ion Implantation on DLC Preparation Using PBIID Process", IEEE Trans. Plasma Sci., Vol. 34, pp. 1183-1189, 2006.

[100]Y. Wang, L. Wang, Y. Yu, K. Mu and X. Wang, "DLC Film Fabrication on the Inner Surface of a Cylinder by Carbon Ion Implantation", IEEE Trans. Plasma Sci., Vol. 34, pp. 1116-1120, 2006.

[101]J.L. Lauer, J.L. Shohet, R.M. Albrecht, S. Esnault, J.S. Malter, U.H. von Andrian and S.B. Shohet "Control of uniformity of plasmasurface modification inside of small-diameter polyethylene tubing using microplasma diagnostics", IEEE Trans. Plasma Sci., Vol. 33, pp. 791- 798, 2005.

[102]X. Tian, C. Gong, S. Yang, Z. Luo, R.K.-Y. Fu and P.K. Chu, "Oxygen Plasma Ion Implantation of Biomedical Titanium Alloy", IEEE Trans. Plasma Sci., Vol. 34, pp. 1235-1240, 2006.

[103]G.J. Wan, N. Huang, S.C.H. Kwok, Z.Y. Shao, A.S. Zhao, P. Yang and P.K. Chu, "Si-N-O Films Synthesized by Plasma Immersion Ion Implantation and Deposition (PIII\&D) for Blood-Contacting Biomedical Applications", IEEE Trans. Plasma Sci., Vol. 34, pp. 1160-1165, 2006.

[104]Y. Cheng and Y.F. Zheng, "A Study of ZrN/Zr Coatings Deposited on NiTi Alloy by PIIID Technique", IEEE Trans. Plasma Sci., Vol. 34, pp. 1105-1108, 2006.

[105]N. Takeuchi, K. Yasuoka and S. Ishii, "Surface Modification of Thin Rods by Theta-Pinching Metallic Plasmas", IEEE Trans. Plasma Sci., Vol. 34, pp. 1112-1115, 2006.

[106]K. Yukimura, M. Kumagai, K. Takaki, R. Hasegawa, S. Nakamura, S.Mukaigawa and T. Fujiwara, "High deposition rate of amorphous carbon film using a magnetically driven shunting arc discharge", Surf. Coat. Technol., Vol. 196, pp. 203-206, 2005.

[107]W.-O. Siew, K.-H. Wong, S.-S. Yap and T.-Y. Tou, "Space and timeresolved optical emission spectroscopy in TEA- $\mathrm{CO}_{2}$ laser ablation of polymers and graphite", IEEE Trans. Plasma Sci., Vol. 33, pp. 176$182,2005$.

[108]I. Brown and E. Oks, "Vacuum arc ion sources: recent developments and applications", IEEE Trans. Plasma Sci., Vol. 33, pp. 1931-1943, 2005.

[109]D. Leonhardt, C. Muratore and S.G. Walton, "Applications of electron-beam generated plasmas to materials processing", IEEE Trans. Plasma Sci., Vol. 33, pp. 783-790, 2005.

[110]A. Lorusso, F. Belloni, D. Doria, V. Nassisi, J. Wolowski, J. Badziak, P.Parys, J. Krasa, L. Laska, F.P. Boody, L. Torrisi, A. Mezzasalma, A.Picciotto, S. Gammino, L. Calcagnile, G. Quarta and D. Bleiner, "Modification of materials by high energy plasma ions", Nucl. Instrum. Methods Phys. Res. B, Vol. 240, pp. 229-233, 2005.

[111]T.A. Edison, "Process of duplicating phonograms", U.S. Patent 484 582, Oct. $18,1892$.

[112]A.F. Rogozin and R.P. Fontana, "Reactive gas-controlled arc process", IEEE Trans. Plasma Sci., Vol. 25, pp. 680-684, 1997.

[113]F.-R. Weber, F. Fontaine, M. Scheib and W. Bock, "Cathodic arc evaporation of $(\mathrm{Ti}, \mathrm{Al}) \mathrm{N}$ coatings and $(\mathrm{Ti}, \mathrm{Al}) \mathrm{N} / \mathrm{TiN}$ multilayercoatings-correlation between lifetime of coated cutting tools, structural and mechanical film properties", Surf. Coat. Technol., Vol. 177-178, pp. 227-232, 2004. 
[114]C. Zheng, D. Zhu, D. Chen, Z. He, L. Wen, W.Y. Cheung and S.P.Wong, "Influence of $\mathrm{O}_{2}$ Flow Rate on Structure and Properties of $\mathrm{MgOx}$ Films Prepared by Cathodic-Vacuum-Arc Ion Deposition System", IEEE Trans. Plasma Sci., Vol. 34, pp. 1099- 1104, 2006. $\mathrm{K}$. Yukimura and Y. Tani, "Generation of triggerless silicon shunting plasma and ion extraction", Surf. Coat. Technol., Vol. 142/144, pp. 388-391, 2002.

[115]K. Takaki, O. Kumagai, R. Hasegawa, S. Mukaigawa, T. Fujiwara, M.Kumagai and K. Yukimura, "Characteristics of magnetically driven shunting arc plasma for amorphous carbon film deposition", Thin Solid Films, Vol. 506-507, pp. 150-154, 2006.

[116]K. Yukimura, K. Ego, K. Takaki, S. Mukaigawa and T. Fujiwara, "Amorphous carbon film deposition by PBII\&D using shunting arc discharge", Nucl. Instrum. Methods Phys. Res. B, Vol. 242, pp. 321323, 2006.

[117]M.S. Trtica , V.F. Tarasenko, B.M. Gakovic, A.V. Fedenev, L.T.Petkovska, B.B. Radak, E.I. Lipatov and M.A. Shulepov, "Surface modifications of TiN coating by pulsed TEA $\mathrm{CO}_{2}$ and XeCl lasers", Appl. Surf. Sci., Vol. 252, pp. 474-482, 2005.

[118]R.W. Bruce, R.L. Bruce, A.W. Fliflet, M. Kahn, S.H. Gold, A.K.Kinkead, D. Lewis, III and M.A. Imam, "Joining of ceramic tubes using a high-power 83-GHz Millimeter-wave beam", IEEE Trans. Plasma Sci., Vol. 33, pp. 668- 678, 2005.



Hidenori Akiyama (M'87-SM'99-F'00) received the Ph.D. degree from Nagoya University, Nagoya, Japan, in 1979. From 1979 to 1985 , he was a Research Associate at Nagoya University. In 1985, he joined the faculty at Kumamoto University, Japan, where he is currently a Professor. He received the IEEE Major Education Innovation Award in 2000 and the IEEE Peter Haas Award in 2003.

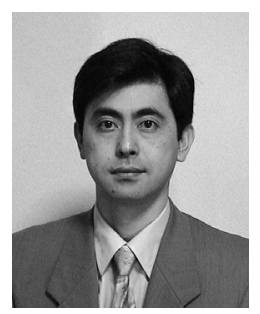

Takashi Sakugawa (M’05) received the M.S. and $\mathrm{Ph} . \mathrm{D}$. degrees from Kyushu University, Japan, in 1989 and Kumamoto University, Japan, in 2004, respectively. He worked at Meidensha Corporation from 1989 to 2004. He is currently an Associate Professor at Kumamoto University.

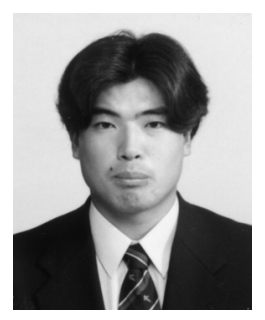

Takao Namihira (M'00-SM'05) was born in Shizuoka, Japan, on 23 January 1975 . He received the B.S., M.S. and Ph.D. degrees from Kumamoto University, Japan, in 1997, 1999, and 2003, respectively. From 1999 to 2006, he was a Research Associate at Kumamoto University, where he is currently an Associate Professor. During 2003-2004, he was on sabbatical leave at the Center for Pulsed Power and Power Electronics, Texas Tech University, Lubbock. His current interests are basic and applied research of ns pulsed discharge plasma.

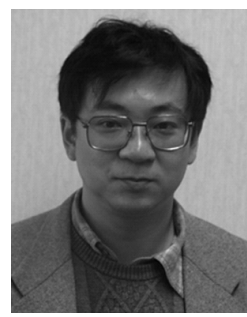

Koichi Takaki (M'99) was born in Fukuoka, Japan, on 16 October 1963. He received the B.S., M.S. and Ph.D. degrees from Kumamoto University, Japan, in 1986, 1988 and 1995, respectively. In 1989 and 1993, he became a Research Associate and Lecturer at Oita National College of Technology, respectively. From 1996 to 2000, he was a Research Associate at Iwate University, Japan, where he is currently an Associate Professor. During 2000-2001, he was a Visiting Scientist at the McMaster University, Canada. His current interests are basic and applied research in various aspects of gaseous discharge and pulsed power.

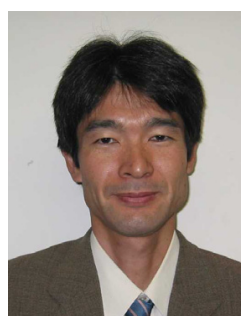

Yasushi Minamitani (M'04) received the M.S. and $\mathrm{Ph} . \mathrm{D}$. degrees from Kumamoto University, Japan, in 1988, and 1999, respectively. From 1988 to 2000, he worked at Mitsubishi Electric Corporation, Japan. From 2003 to 2004, he was with Old Dominion University, Norfolk, where he studied the pulsed power applications to physics and environmental fields. $\mathrm{He}$ is currently an Associate Professor at Yamagata University, Japan.

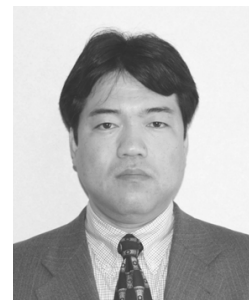

Naoyuki Shimomura (M'97) was born in Fukuoka, Japan. He received the B.S., M.S., and Ph.D. degrees from Kumamoto University, Japan, in 1987, 1989, and 1996 respectively. In 1990, he joined the University of Tokushima, Japan, as a Research Associate. He is currently an Associate Professor. During 1997-1998, he was on sabbatical leave at the University of New Mexico and Air Force Research Laboratory, Albuquerque. 